\title{
Abanicos arenosos de aguas profundas estructuralmente confinados: Formación Mezcala del Cretácico Superior, cuenca Taxco-Atlixtac, norte del Estado de Guerrero, México
}

\author{
Yam Zul Ernesto Ocampo-Díaz ${ }^{1, *}$ y Martin Guerrero-Suastegui ${ }^{2}$ \\ ${ }^{1}$ Área de Ciencias de la Tierra, Facultad de Ingeniería, Universidad Autónoma de San Luís de Potosí, \\ Av. Dr. Manuel Nava No. 8, Zona Universitaria, C.P., 78290, San Luís, Potosí, México. \\ ${ }^{2}$ Unidad Académica de Ciencias de la Tierra, Universidad Autónoma de Guerrero, \\ ex-Hacienda de San Juan Bautista, S/N, Taxco el Viejo, Guerrero, México. \\ *magonegro_2000@hotmail.com
}

\section{RESUMEN}

Un análisis sedimentológico detallado de la Formación Mezcala permitió hacer una diferenciación de 22 facies sedimentarias, la interpretación de los mecanismos de transporte de sedimentos, los ambientes de depósito y sus relaciones con el marco tectónico regional. El trabajo consistió en cartografía de facies y de la relación arenisca-lutita, análisis de paleocorrientes y de datos paleontológicos documentados en la región norte de la cuenca Taxco-Atlixtac. Las facies diferenciadas sugieren transporte por flujos de masas por gravedad y episodios de crecidas en forma de manto, asociados con períodos de tormenta. Se interpretó que las sucesiones sedimentarias corresponden a ambientes de aguas profundas. Ocho asociaciones de facies conforman tres Sucesiones Sedimentarias Profundas (SSP) y dos dominios de sedimentación. En orden cronoestratigráfico, éstos son: Huixtac-Ojo de Agua (CTH-OA) y Cerro Gordo-Taxco el Viejo. Las evidencias sedimentológicas muestran el desarrollo de sistemas canalizados de tipo erosivo, mixto y de depósito, transición lóbulo-canal, depósitos de planicie de inundación, lóbulos, depósitos de intercanal y en planicie de cuenca.

El CTH-OA está conformado por las SSP-1, 2 y 3, con una edad del Cenomaniano temprano al Turoniano tardío. En orden cronoestratigráfico, las direcciones de paleocorrientes en los sistemas canalizados varían de $\mathrm{SE} 85^{\circ}$ a NW $10^{\circ}$, en tanto que las sucesiones de lóbulos varían de $\mathrm{SE} 60^{\circ}$ a NW20 ${ }^{\circ}$. El CTCG-TV está conformado por las SSP-2 y SSP-3, en las cuales los sistemas canalizados presentan direcciones que varían de $\mathrm{SE} 10^{\circ}$ a SW ${ }^{\circ} 40$, en tanto que los sistemas de lóbulo muestran direcciones de paleocorrientes desde SE $20^{\circ}$ hasta $\mathrm{NW} 60^{\circ}$. Los patrones de paleocorrientes y el análisis de facies indican que la cuenca de TaxcoAtlixtac estuvo confinada por altos estructurales y que el sedimento se distribuyó en el eje del cinturón orogénico.

El relleno de la cuenca de Taxco-Atlixtac se efectuó en tres fases de sedimentación relacionadas con procesos de colisión "suave" $v s$. "dura" de los terrenos Guerrero y Mixteca, en un sistema de subducción hacia el suroeste. La fase 1 está relacionada con un proceso de colisión "suave" ocurrido en el Cenomaniano temprano y con el desarrollo de abanicos submarinos ricos en lodos-arenas del CTH-OA (SSP-1). La sedimentación ocurrió dentro de una cuenca de tipo antefosa (foredeep) simple relacionada con el origen y desarrollo de la cuenca de Pachivia. La fase 2 está relacionada con el proceso de colisión "dura" del subterreno Teloloapan contra el Terreno Mixteca, que favoreció la migración de la antefosa hacia la región de Taxco y el cambio de un antefosa simple a una compleja, y a un mayor desarrollo del cinturón orogénico durante el Cenomaniano tardío-Turoniano temprano. Este proceso de colisión "dura” generó el mayor confinamiento de la cuenca de Taxco-Atlixtac, el desarrollo de una inflexión tectónica positiva (forebulge) y el depósito de abanicos submarinos ricos en arenas y lodos que conforman ambos complejos turbidíticos (SSP-2). La fase 3 representa un periodo de relajación y de poco crecimiento del cinturón orogénico que propició el desarrollo de abanicos ricos en lodo-arenas en ambos dominios de sedimentación (SSP-3), así como la colmatación de la cuenca de Taxco-Atlixtac durante el Turoniano tardío, posiblemente favorecido por un segundo proceso de colisión "suave".

Palabras clave: Formación Mezcala; cuencas antepaís; antefosa; abanicos submarinos; turbiditas; Terreno Guerrero.

\begin{abstract}
A detailed sedimentologic study of the Mezcala Formation allowed the differentiation of 22 sedimentary facies, the interpretation of the mechanisms of sediment transportation, environments of deposition and their relationships with the regional tectonic framework. The field study consisted of facies cartography, as well as the mapping of sandstone-shale ratios, paleocurrents and paleontological data analysis in the northern portion of the Taxco-Atlixtac basin. The facies distinction suggest gravity mass flows and episodic sheet flows related to storm periods. Sedimentary sequences are related to deep water environments. Eight facies associations constitute three Deep Sedimentary Sequences (SSP, as for their initials in spanish) and two sedimentation domains. These are, in chronostratigraphic order: Huixtac-Ojo de Agua (H-OATC) and Cerro Gordo-Taxco el Viejo (CG-TVCT). Both H-OATC and CG-TVCT domains developed erosive, mixed, and lobe depositional systems as well as transitional lobe-channels, interchannel systems, overbank and basin plain deposits.

The H-OATC is composed of SSP-1, SSP-2, and SSP-3 of late Turonian age. The paleocurrents patterns vary from $S E 85^{\circ}$ to $\mathrm{NW} 10^{\circ}$
\end{abstract}


directions in the channelized systems, while the lobe successions vary from $S E 60^{\circ}$ to $N W 20^{\circ}$. The CG-TVCT includes SSP-2 and SSP-3, where the channelized systems show sediment dispersal variations from $S E 10^{\circ}$ to $S W^{\circ} 40$; on the other hand, the lobes systems have paleocurrent directions that varies from $S E 20^{\circ}$ to $N W 60^{\circ}$. Paleocurrent patterns and facies analysis indicate that the Taxco-Atlixtac basin was confined by structural highs, and had a sedimentation distribution on the axis of the orogenic belt.

The filling of the Taxco-Atlixtac basin took place in three sedimentation phases, which were related to "soft vs. hard", southwesternwards subduction processes between the Guerrero and Mixteca terranes. Phase 1 is related to a soft-collision process, during early Cenomanian time, which deposited the CTH-OA sand-rich submarine fans within a simple foredeep basin associated to the origin and development of the Pachivia basin. Phase 2 is related to the Teloloapan subterrane and Mixteca terrane hard-collision process, which favored the migration of the foredeep to the Taxco region, and the change from a simple to a complex foredeep. Also, the development of an orogenic belt took place during late Cenomanian and early Turonian time. This hard-collision process generated an improved confinement of the Taxco-Atlixtac basin, the development of an elevated flexure region and sand-rich and mud-rich submarine fan systems that formed both turbiditic complexes. Phase 3 was a period of relaxation and small growth of the orogenic belt, which developed mudsand rich submarine fans in both sedimentation domains (DSS-3), as well as the complete filling of the Taxco-Atlixtac basin during late Turonian, possibly caused by a second soft-collision process.

Key words: Mezcala Formation; foreland basins; foredeep; submarine fans; turbidites; Guerrero Terrane.

\section{INTRODUCCIÓN}

El sistema de antepaís del cinturón plegado y cabalgado del sur de México se caracterizó por una migración continua de los depocentros hacia el oriente, reflejando el despegue de la parte superior de la litósfera (principalmente la cobertura) como resultado de la acreción-amalgamación de los terrenos Guerrero y Mixteca durante el Cretácico Temprano al Cretácico Tardío (Guerrero-Suastegui, 2004; Guerrero-Suastegui et al., 2006a, 2006b; 2010; Figuras 1a y 1b). El inicio de estas cuencas de antepaís del cinturón plegado se desarrolló en ambientes marinos profundos, formando depocentros alargados y aislados (Guerrero-Suastegui et al., 2010), que posteriormente evolucionaron a sistemas marinos profundos y someros dentro de depocentros alargados y continuos (Lawton et al., 2016; Ocampo-Díaz et al., 2016). En la zona de estudio en el sur de México, se ha identificado la zona de antefosa (foredeep) de las cuencas de antepaís en las regiones de Miahuatepec, Pachivia y Taxco-Atlixtac (Guerrero-Suastegui et al., 2010). Durante el Albiano tardío al Turoniano temprano, las cuencas de antefosa de las regiones de Miahuatepec y Pachivia fueron rellenadas por turbiditas de grano fino, caracterizadas por sistemas de lóbulo y depósitos de canal-desbordamiento (overbank), dentro de sistemas de abanico submarino ricos en lodos (Guerrero-Suastegui, 2004; Guerrero-Suastegui et al., 2006b y 2010; Figura 1). En tanto, durante el Cenomaniano tardío al Coniaciano, las depozonas de antefosa de Taxco-Atlixtac y Zacacoyuca-Maxela fueron rellenadas por sistemas turbidíticos arenosos-lodosos que conforman sistemas de lóbulo y canales de desbordamiento (overbank), con características similares a los sistemas de abanicos ricos en arenas y lodos (Guerrero-Suastegui, 2004; Ocampo-Díaz, 2004; Hurtado-Brito et al., 2006; Hurtado-Brito y Castillo-Delgado, 2009; Guerrero-Suastegui et al., 2010; OcampoDíaz, 2012; Figura 1).
La Formación Mezcala, en la cuenca de Taxco-Atlixtac, es la primera unidad de turbiditas arenosas depositadas dentro de una antefosa simple que evolucionó a una antefosa compleja "confinada" (Ocampo-Díaz, 2012), rellenada con aporte longitudinal de sedimentos derivados del cinturón orogénico durante el Cenomaniano tardío al Turoniano tardío (Estrada-Flores, 1995; Ocampo-Díaz, 2004; OcampoDíaz, 2012).

La Formación Mezcala se dividió informalmente en los miembros profundo y somero (González-Pacheco, 1991). El miembro profundo es el más antiguo y aflora en las regiones más occidentales con edades que varían del Albiano tardío al Coniaciano (Estrada-Flores, 1995; Guerrero-Suastegui, 2004; Guerrero-Suastegui et al., 2010; OcampoDíaz, 2012; Figuras 1 y 2). Por otro lado, el miembro somero más joven, aflora en las localidades más orientales con edades que varían del Coniaciano al Maastrichtiano (González-Pacheco, 1991; AguileraFranco et al., 1998 y 2001; Hernández-Romano et al., 1997; 1998; Guerrero-Suastegui et al. 2010), dentro de las cuencas denominadas Maxela y Chilapa (Guerrero-Suastegui et al., 2006b).

Las antefosas confinadas dentro del sistema de antepaís son cuencas sedimentarias restringidas topográficamente o con cambios abruptos en la morfología, con lóbulos con morfología alargada, desarrollando un canal de desvío (by pass) asociado con altos estructurales (e.g., pliegues o fallas inversas; Ricci-Lucchi, 1986), y presentan paleocorrientes bidireccionales del tipo bipolar y/o polimodal (Pickering y Hiscott, 1985; Kneller et al., 1991). Por tal motivo, el análisis de direcciones de paleocorrientes es una herramienta muy importante para determinar altos estructurales o canales de desvío, como también, la morfología de los depósitos, sobre todo cuando éstos han sido soterrados por sucesiones gruesas turbidíticas o moderadamente deformados. En los sistemas turbidíticos no confinados, las direcciones de paleocorrientes de estructuras unidireccionales (e.g., surcos de erosión), tienen patrones con direcciones generalmente perpendiculares al cinturón orogénico, mientras, que en las partes distantes se presentan de forma radial como resultado de la dispersión de la carga media y final de las corrientes turbidíticas. El caso contrario son los patrones de paleocorrientes dentro de una antefosa confinada, los cuales son, generalmente, oblicuos o axiales al cinturón orogénico, lo cual favorece el desarrollo de lóbulos alargados bipolares (Kneller et al., 1991). La refracción de las corrientes turbidíticas es un proceso común en los sistemas de antefosa confinada; este proceso puede ser visualizado por el análisis de los vectores promedio de paleocorrientes de las rizaduras, los cuales muestran direcciones oblicuas a los surcos de erosión. Los procesos de refracción y reflexión de las corrientes turbidíticas han sido interpretados como el resultado de la bifurcación de una gran parte del gran volumen de la corriente turbidítica (Pickering y Hiscott, 1985; Wynn et al., 2002a y 2002b; Lomas y Joseph, 2004). De acuerdo con Pickering et al. (1988), Guerrero-Suastegui (2004) y Pickering y Hiscott (2016), los sistemas turbidíticos confinados, comúnmente son rellenados por sistemas de baja eficiencia, es decir, por sistemas de abanicos submarinos ricos en arenas-lodos, arenas y gravas (Reading y Richards, 1994), en tanto, que los sistemas turbidíticos no confinados son rellenados por sistemas de alta eficiencia, en este caso por sistemas de abanicos submarinos ricos en lodos y lodos-arenas (Reading y Richards, 1994). Pickering et al. (1988) documentan que los sistemas de alta eficiencia están relacionados comúnmente con procesos de colisión suave, mientras que los procesos de colisión dura, desarrollan sistemas de baja eficiencia. Por esta razón, y para evitar ambigüedad en los diferentes conceptos de colisión, en este trabajo se tomó la propuesta de Pickering et al. (1988) quienes definen colisión "como el momento en que placas de corteza no oceánica con vergencia opuesta entran en contacto, por ejemplo, corteza anómala tal como en arcos de islas, crestas asísmicas y montes submarinos, corteza continental 
$101^{\circ}$

$100^{\circ}$

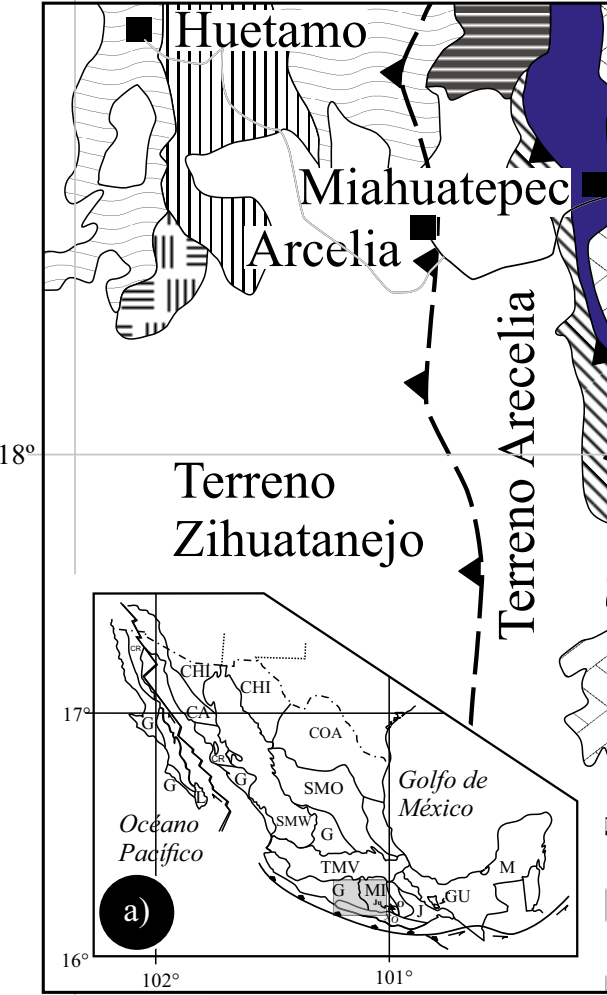

$101^{\circ}$

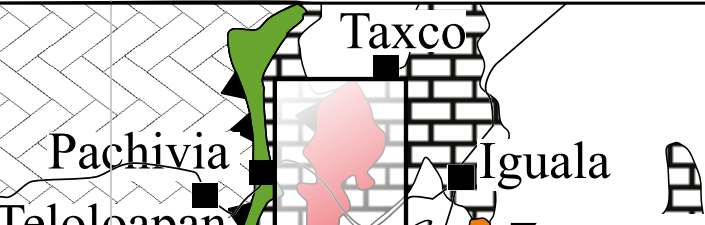

b)
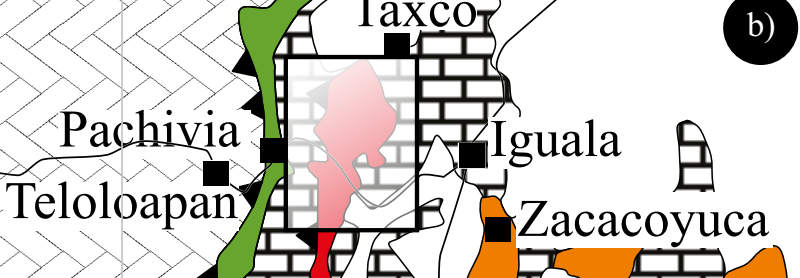

ज]
$\frac{0}{0}$
$\frac{0}{0}$
$\frac{0}{0}$

<

101

$\pi$

$>>$

$\int_{5}$ य 3 Maxela'

$\int_{0}^{1}$ A

อี

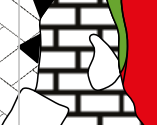

-icapar
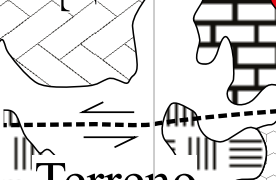

$\|$ Terreno

IIIXolapal

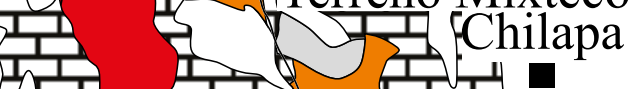

ער

Chilpancingo

Chilpancin
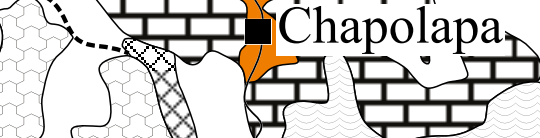

$100^{\circ}$

Terreno Zihuatanejo

Rocas de arco en el área de Huetamo: volcaniclásticas marinas, calizas y algunos flujos de lava y piroclastos.

Terreno Arcelia

Lavas almohadilladas (MORB; Cretácico) turbiditas volcaniclásticas de grano fino y pedernal de ambientes profundos.

Lavas almohadilladas (IAB, Cretácico), turbiditas volcaniclásticas de grano fino y pedernal de ambientes profundos.

\section{Terreno Teloloapan} Rocas de arco (Cretácico Inferior: lavas andesíticas a basálticas y rocas volcaniclásticas, calizas arrecifales masivas (este); lavas marinas profundas, flujos de escombro calcáreo y turbiditas volcaniclásticas (oeste).

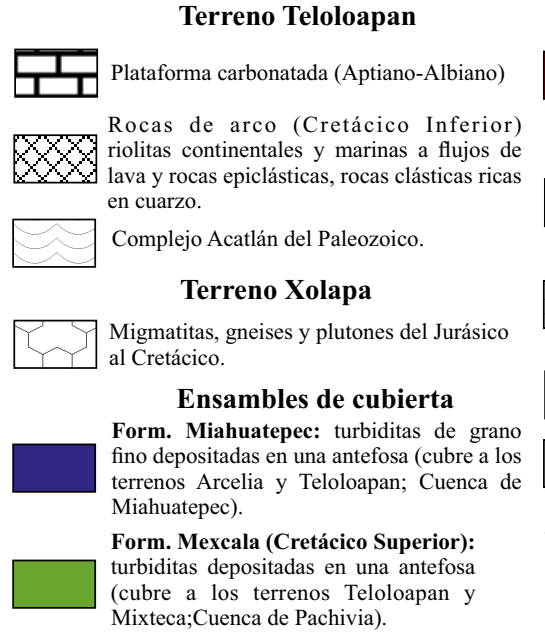

Terreno Teloloapan

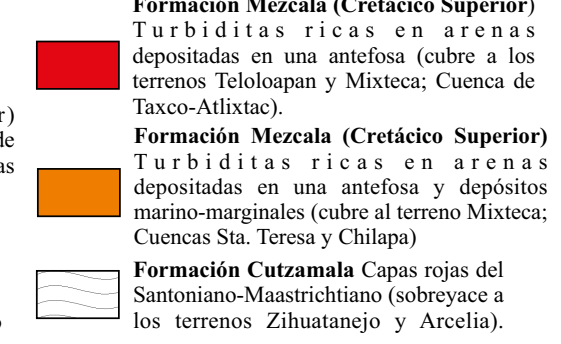

= IIIT Granitoides del Cretácico Superior al EயW $=$ Paleógeno

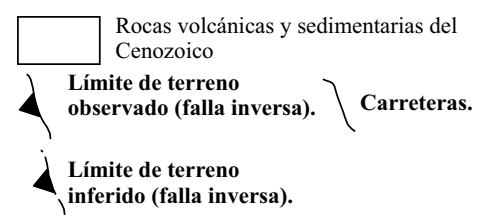

Figura 1. Localización del área de estudio. a) Distribución de terrenos tectono-estratigráficos de México. Tomada de Campa y Coney (1983); b) Mapa geológico detallado que muestra los límites de los terrenos que conforman al Terreno Guerrero y sus límites con los terrenos Mixteca y Xolapa. Adaptado y modificado de Centeno-García et al. (2008, 2011), con la nomenclatura propuesta por Ramírez-Espinoza et al. (1991). Abreviaturas: G: Guerrero; CHI: Chihuahua; COA: Coahuila; SMO: Sierra Madre Oriental; SMW: Sierra Madre Occidental; TMV: Cinturón Volcánico Mexicano; CA: Caborca; MI: Mixteca; J: Juárez; XO: Xolapa; O: Oaxaca; M: Maya. El recuadro en color gris denota el área trabajada en detalle.

de espesor promedio y constante". Así mismo, estos autores establecen que la colisión inicial puede ser suave, esto es, sin orogénesis mayor asociada a través de la(s) sutura(s) de colisión, mientras que la colisión sostenida relacionada con procesos efectuados durante decenas de millones de años, puede llevar a la culminación de una orogenia mayor; los mismos autores consideran que durante la "colisión dura" se establecen patrones regionales de deformación donde se generan y cierran nuevos relojes isotópicos. La determinación e interpretación del tiempo de colisión suave se basa en datos geológicos sutiles como son: grupos faunísticos sensibles como las especies bentónicas, preferiblemente sin desarrollo de etapas pelágicas larvarias (Pickering et al., 1988), desarrollo de sistemas de alta energía dentro de la cuenca o de tormenta en la margen de la plataforma (Guerrero-Suastegui, 2004) y la generación de sistemas hiperpicnales que delimitan cada uno de los sistemas profundos (Ocampo-Díaz, 2012).

El objetivo principal del presente trabajo es documentar la evolu- 


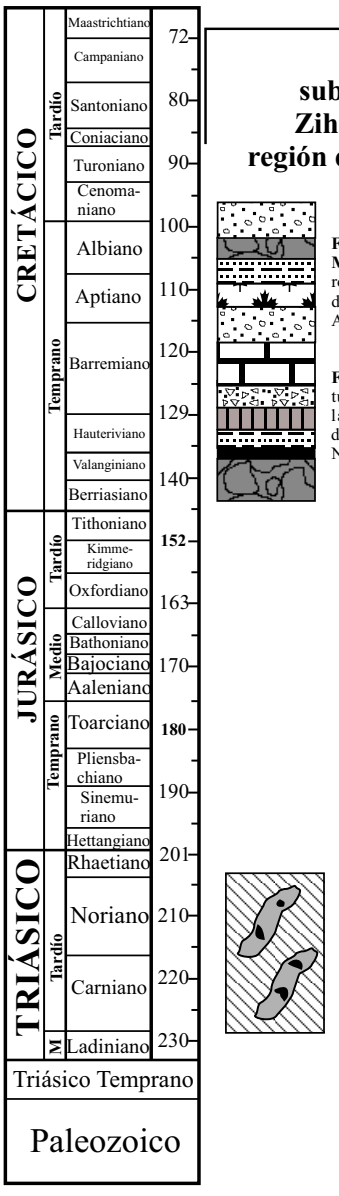

Terreno Guerrero

$$
\begin{gathered}
\text { subterreno } \\
\text { Arcelia }
\end{gathered}
$$

Zihuatanejo

Formaciones Conburindio Malpaso: calizas marinas somera rocas volcaniclassticas, pocos flujo de lavas andesiticas y basalticas de

Formaciones Angao y San Luca turbiditas volcánicas, pederna lavas félsicas y básicas que desaparecen hacia la cima de
Complejo A r te a ga Nor i a n o-C a r n i a n o Turbiditas ricas en cuarzo y matriz, bloques de lavas almohadillados, pedernal, serpentina y a e e complejo de acreción y c a liza

Figura 2. Columnas estratigráficas de los terrenos Zihuatanejo, Arcelia y Teloloapan que conforman el Terreno Guerrero, y de la parte occidental del Terreno Mixteca (adaptadas de Centeno-García et al., 2008, 2011). *Unidades litoestratigráficas que no afloran en el área de estudio.

ción sedimentológica y el modelo de depósito de la Formación Mezcala en la región norte de la cuenca de Taxco-Atlixtac (Figura 1). Se hizo el análisis de 250 perfiles sedimentológicos-estratigráficos de escalas variables, cartografía de facies, cartografía geológica, levantamiento de $\sim 800$ datos de paleocorrientes (e.g. surcos de erosión y estructuras de arrastre) y análisis de datos paleontológicos documentados por diversos autores.

\section{MARCO GEOLÓGICO REGIONAL}

El área de estudio se localiza en el terreno Mixteca, cerca del límite con el terreno Guerrero (Figura 1a). El terreno Mixteca consiste en un basamento de rocas metamórficas polideformadas, pre-misisípicas denominadas Complejo Acatlán. Este es considerado como el resultado de interacciones complejas entre Gondwana y Laurencia, previas y durante el ensamble de Pangea (Ortega-Gutiérrez, 1981; OrtegaGutiérrez et al., 1999; Ramírez-Espinosa, 2001; Centeno-García et al., 2008). García-Díaz (2004) sugiere que a este complejo metamórfico le sobreyacen discordantemente rocas sedimentarias pérmicas, que, a su vez, están cubiertas por rocas volcánicas y sedimentarias denominadas Ignimbrita Las Lluvias del Jurásico Medio (Figura 2). Hacia la parte más occidental de este terreno, en las cercanías del límite con el Terreno Guerrero, afloran rocas volcánicas, volcaniclásticas y sedimen- tarias parcialmente metamorfizadas llamadas Esquisto Taxco y Roca Verde Taxco el Viejo (Campa, 1975), en el área de Taxco y Taxco el Viejo, respectivamente; en la región de Teloloapan se han denominado como formaciones Villa Ayala y Acapetlahuaya (Ramírez-Espinoza et al., 1991; Guerrero-Suastegui, 2004; Centeno-García et al., 2008), en tanto que en la región sur de Chilpancingo se ha denominado como Forrmación Chapolapa (Talavera-Mendoza, 1993; Centeno-García et al., 2008; Campa-Uranga et al., 2012; Sierra-Rojas et al., 2016; Figura 2).

El Esquisto Taxco y la Roca Verde Taxco el Viejo consisten en lavas andesíticas a riolíticas y rocas volcaniclásticas del Cretácico Inferior (Hauteriviano-Valanginiano; Talavera-Mendoza, 1993; Talavera-Mendoza et al., 2007; Campa-Uranga et al., 2012). Estas unidades metamórficas están cubiertas por una gruesa sucesión de calizas del Albiano al Cenomaniano, y por rocas clásticas del Cenomaniano superior al Turoniano superior (formaciones Morelos y Mezcala, respectivamente; Ocampo-Díaz, 2004; Guerrero-Suastegui, 2004). El Terreno Guerrero cabalga al Terreno Mixteca (Figura 1), y está conformado por un basamento metamórfico del Triásico denominado Complejo Arteaga. A éste le sobreyacen discordantemente conjuntos de arco submarino desarrollados en un ambiente intraoceánico (Campa y Coney, 1983; Tardy et al., 1994; Centeno-García et al., 2008; Martini et al., 2014), que se acrecionó al México nuclear durante el Albiano-Cenomaniano (Centeno-García et al., 2003; García-Díaz, 2004; Centeno-García et al., 2008; Martini et al., 2014; 
Ocampo-Díaz et al., 2016). De acuerdo con Ramírez-Espinoza et al. (1991) y Centeno-García et al. (2008), el Terreno Guerrero está formado por los subterrenos Teloloapan, Arcelia-Palmar Chico y Zihuatanejo-Huetamo (Figura 2). El subterreno Teloloapan es una unidad volcano-sedimentaria que representa la parte más oriental del Terreno Guerrero, con aproximadamente $100 \mathrm{~km}$ de ancho y $300 \mathrm{~km}$ de longitud. Este subterreno consiste en una sucesión de lavas básicas a intermedias, masivas y almohadilladas, así como hialoclastitas, con un espesor aproximado de $300 \mathrm{~m}$ (Guerrero-Suastegui, 2004). Los niveles más inferiores de las rocas volcánicas están intercalados con lutitas, pedernal y limolitas con radiolarios del Cretácico Temprano. Los niveles superiores consisten en flujos de lava intercalados con depósitos de flujos de escombros y capas discontinuas de calizas del Aptiano (Guerrero et al., 1991; Guerrero-Suastegui, 2004). Estas rocas volcánicas están cubiertas por una gruesa sucesión de calizas arrecifales y bioclásticas, litarenitas ricas en matriz y lutitas tobáceas $(\sim 1500 \mathrm{~m})$, y por una sucesión de lutita y arenisca turbidíticas del Turoniano (Campa y Ramírez, 1979; Talavera-Mendoza et al., 1995; Monod et al., 2000). En esta última sucesión, Guerrero-Suastegui (2004) reporta una edad del Cenomaniano-Turoniano. El Terreno Arcelia-Palmar Chico consiste en una unidad volcánica que incluye lavas almohadilladas, almohadillas brechadas y hialoclastitas con un espesor de $\sim 2000 \mathrm{~m}$. La unidad está intrusionada por numerosos diques doleríticos (diabasa) (Talavera-Mendoza et al., 2007). Hacia la parte superior de la sucesión volcánica se encuentran horizontes de lutitas negras y pedernal rico en radiolarios (Figura 2). Pequeños cuerpos de gabro serpentinizado y rocas ultramáficas están estructuralmente asociados con las lavas almohadilladas y rocas sedimentarias. Fechamientos radiométricos y determinaciones paleontológicas restringen la edad del ensamble de Arcelia-Palmar Chico al Albiano-Cenomaniano (Delgado-Argote et al., 1990; Dávila y Guerrero, 1990; Guerrero-Suastegui, 2004). El Terreno Zihuatanejo-Huetamo tiene un basamento Triásico constituido por turbiditas ricas en cuarzo, tectónicamente imbricadas, denominado Complejo Arteaga o Complejo Las Ollas (Talavera-Mendoza, 2000; Centeno-García et al., 2008). El Complejo Arteaga, de edad Triásico (Ladiniano-Noriano; Campa et al., 1982, y Centeno-García et al., 2008; Figura 2) está constituido por turbiditas ricas en cuarzo (lutita $\mathrm{y}$ arenisca), pedernal negro y verde, tobas máficas que forman un mélange tectónico constituido por basaltos almohadillados, diabasa, gabro bandeado, pedernal y caliza; todo este conjunto está deformado (Talavera-Mendoza, 2000; Centeno-García et al., 2003; 2008; Figura 2). De acuerdo con Mendoza y Suastegui (2000), la sucesión del Terreno Zihuatanejo-Huetamo consiste en más de $2000 \mathrm{~m}$ de rocas volcánicas de arco y rocas sedimentarias del Cretácico Temprano (Albiano). La parte inferior de la sucesión son $\sim 1500 \mathrm{~m}$ de flujos de lava andesítica a dacítica intercalada con turbiditas volcaniclásticas; en la parte superior afloran abundantes ignimbritas félsicas con depósitos de caída. Las rocas sedimentarias del Terreno Zihuatanejo-Huetamo se hacen más antiguas hacia la región central de México, como lo ha documentado Grajales y López (1984, en Centeno-García et al., 2008) quienes documentan una edad del Neocomiano en la región de Colima. Este elemento tectónico es el más grande de todos los subterrenos del Terreno Guerrero y se extiende desde Zihuatanejo hasta Zacatecas (Talavera-Mendoza, 1993; Centeno-García et al., 2008).

\section{Litoestratigrafía del área de estudio}

Los primeros trabajos formales que describen las unidades estratigráficas de los estados de Guerrero y Morelos son los de Fries (1960), Ontiveros-Tarango (1973) y de Cserna (1978). El presente estudio está restringido a la Formación Mezcala, por lo cual las edades, definiciones y relaciones estratigráficas, se basan en las propuestas por OcampoDíaz (2004), las cuales se describen a continuación.

\section{Roca Verde Taxco Viejo (RVTV)}

La RVTV, en el área de estudio, está constituida por metabrechas, metaconglomerados y metalavas-metatobas líticas (Campa, 1975; Talavera-Mendoza, 1993). Las metabrechas y los metaconglomerados exhiben una textura foliada clástica relicta. Las metatobas líticas tienen una textura piroclástica relicta compuesta por feldespatos y fragmentos líticos inmersos en una mesostasis afanítica, parcial o completamente milonitizada, con foliación que da una textura sedosa. Los líticos son fragmentos aplanados de metatobas y pizarras (Campa et al. 1974; Figura 2). Esta unidad aflora en las inmediaciones de Taxco el Viejo donde sobreyace a la Formación Morelos por medio de una falla inversa (Figura 3). De acuerdo con Ocampo-Díaz (2004 y 2012), dentro de este contacto es común observar bloques de calizas de tipo grainstone de bioclastos (Figura 2).

Las edades determinadas por Campa-Uranga e Iriondo (2004), Talavera-Mendoza et al. (2007) y Campa-Uranga et al. (2012) por medio del método $\mathrm{U}-\mathrm{Pb}$ en circones magmáticos para esta sucesión varían de 129 a $145 \mathrm{Ma}$ (Berriasiano-Hauteriviano; Figura 2).

\section{Formación Morelos}

La Formación Morelos (Fries, 1960), en el área de estudio, está constituida por una sucesión de caliza y dolomía, de estratificación delgada a muy gruesa, que varían de tipo wackestone a packstone de rudistas, nerineidos, caprínidos y gasterópodos, con laminaciones paralelas, estructuras fenestrales y estilolitas (González-Pacheco, 1991; Aguilera-Franco, 1995; Aguilera-Franco et al. 1998; Ocampo-Díaz, 2004). Algunos autores han reportado foraminíferos bentónicos: miliólidos, lituólidos, rotalínidos, dacycladaceas y algas calcáreas (AguileraFranco, 1995; Aguilera-Franco et al. 1998; Hernández-Romano et al., 1997; 1998). Esta unidad se ha interpretado como depósitos de una plataforma epicontinental, semi-restringida en condiciones de alta salinidad, desarrollada dentro de las de zonas supra-, inter- y submarea (González-Pacheco, 1991; Martínez, 1994; Hernández-Romano, 1999; Hernández-Romano et al., 1997; Aguilera-Franco y HernándezRomano, 2004).

La Formación Morelos sobreyace, por falla inversa, a la Formación Mezcala al occidente de Huixtac y Paintla (Figura 3); también, subyace por falla inversa a la RVTV en las inmediaciones de Taxco el Viejo, y subyace de manera concordante a la Formación Agua Nueva en las inmediaciones de San Juan Unión, Tecuiziapa y Puente Campuzano (Ocampo-Díaz, 2004; Figura 3). El espesor estimado para esta unidad varía de 600 a $1000 \mathrm{~m}$. La edad asignada para esta formación está comprendida entre el Albiano y el Cenomaniano tardío (Fries, 1960; Ontiveros-Tarango, 1973, Estrada-Flores, 1995; Figura 2).

\section{Formación Agua Nueva}

La Formación Agua Nueva (Ontiveros-Tarango, 1973) está constituida por estratos delgados de caliza de color gris oscuro con lentes o nódulos de pedernal, caliza arcillosa y lutita calcárea, mostrando un predominio de material terrígeno de base a cima (Ocampo-Díaz, 2004). De acuerdo con Ontiveros-Tarango (1973), esta unidad representa depósitos de cuenca profunda; sin embargo, Guerrero y Ramírez (1992) y Ocampo-Díaz $(2004 ; 2012)$ documentaron en la cima de esta unidad, depósitos de tormenta, constituidos por un nivel inferior conglomerádico de bioclastos de moluscos, cubierto por una unidad laminar cíclica con estratificación y laminación cruzada de tipo swaley y hummocky.

La edad documentada por Ontiveros-Tarango (1973) para la Formación Agua Nueva es del Turoniano, con base en su contenido y asociación faunística de microfósiles planctónicos, la cual se correlaciona con la Formación Cuautla. Sin embargo, Estrada-Flores (1995), asigna una edad del Cenomaniano tardío con base en la asociación fósil: Stamiosphaera sphaerica, Stamiopharica conoidea, Pitonella ovalis 

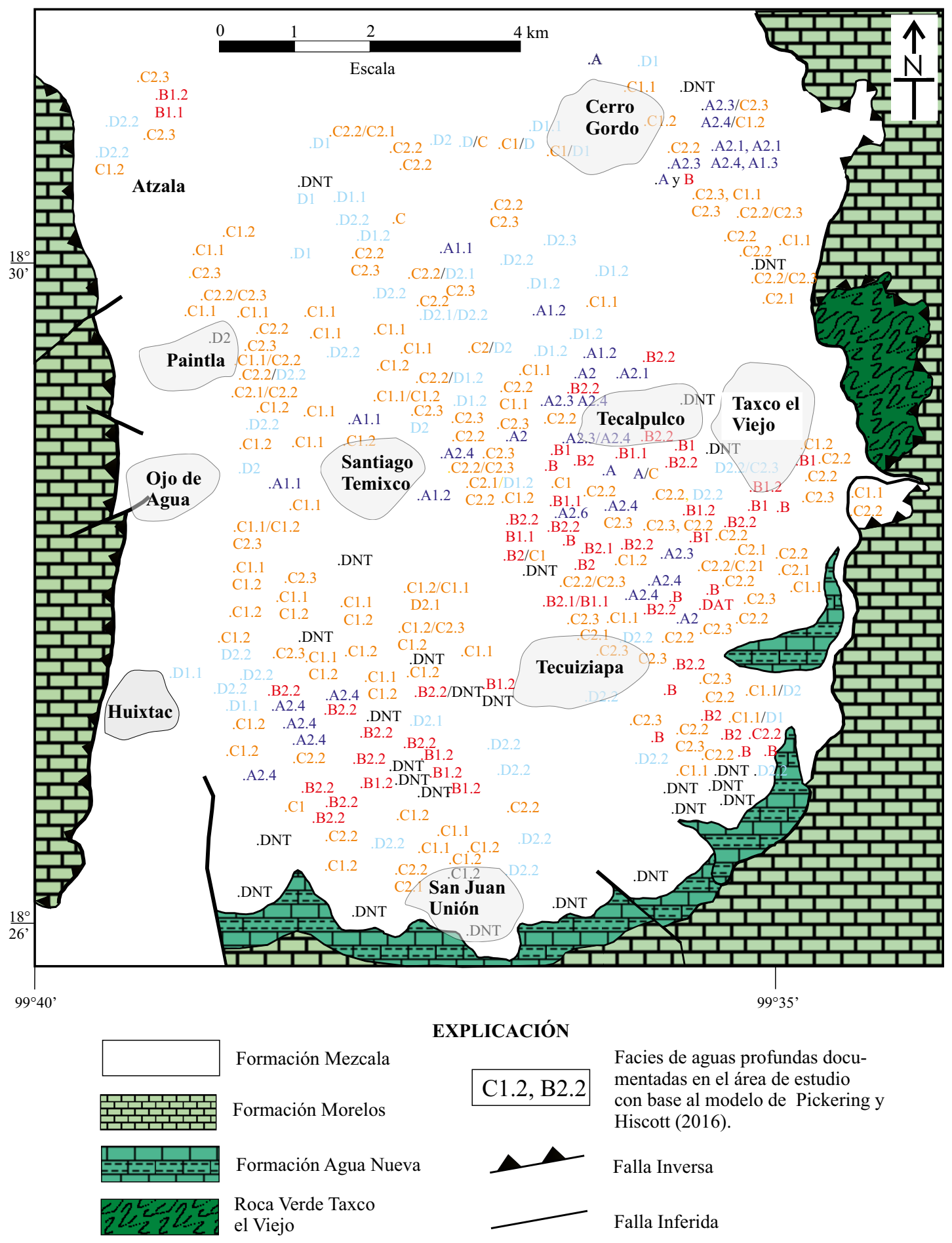

EXPLICACIÓN

Facies de aguas profundas docu-

C1.2, B2.2 mentadas en el área de estudio

con base al modelo de Pickering y

Hiscott (2016).

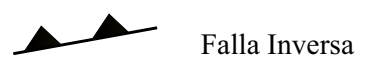

Falla Inferida

Figura 3. Mapa geológico de la parte norte de la cuenca de Taxco-Atlixtac, con los principales rasgos geológicos del área de estudio y las diferentes facies documentadas en este trabajo, según el esquema de facies de Pickering y Hiscott (2016).

y Pitonella trejoi. Esta formación sobreyace y subyace de manera concordante a las formaciones Morelos y Mezcala, respectivamente, y aflora en los límites de la sedimentación terrígena-carbonatada (Figura 3).

\section{Formación Mezcala}

La Formación Mezcala fue definida formalmente por Fries (1960), como una sucesión de capas interestratificadas de arenisca, limolita, lutita calcárea con escasos lentes de caliza, que sobreyacen a las formaciones Cuautla y Morelos. González-Pacheco (1988) dividió esta formación en los miembros "somero", que aflora en los poblados de Atenango del Río-Copalillo (Figura 1), y el miembro "profundo", que se encuentra expuesto en la regiones norte y centro del estado de Guerrero (e.g., Taxco el Viejo, Santa Teresa, Mayanalán, Ahuehuepan; GonzálezPacheco, 1991; Figura 1). De acuerdo a esta subdivisión, las sucesiones que afloran en la cuenca de Taxco-Atlixtac forman parte del miembro 
profundo. En la cuenca de Taxco-Atlixtac, la Formación Mezcala, consiste en intercalaciones de lutita, arenisca de grano fino a muy grueso, arenisca conglomerádica y conglomerados, en proporciones variables (Ocampo-Díaz, 2004 y 2012). El miembro somero se ha interpretado como depósitos de plataforma externa, playa, sistemas deltaicos (frente deltaico somero, prodelta, planicie deltaica), planicie de marea y depósitos de tormenta (González-Pacheco, 1991; Martínez, 1994; Aguilera-Franco, 1995; Hernández-Romano et al., 1997; AguileraFranco et al. 1998; Hernández-Romano, 1999; Aguilera-Franco, 2000; Aguilera-Franco et al., 2001; Aguilera-Franco y Hernández-Romano, 2004; Díaz-Fernández et al., 2006); por otro lado, el miembro profundo ha sido interpretado como depósitos de abanicos submarinos ricos en lodos y en arenas-lodos, depósitos de cuenca profunda y escasos sistemas hiperpicnales (Estrada-Flores, 1995; Guerrero-Suastegui, 2004; Ocampo-Díaz, 2004; Guerrero-Suastegui et al., 2006a; Hurtado-Brito et al., 2006; Hurtado-Brito y Castillo-Delgado, 2009; Martínez, 2009; Ocampo-Díaz, 2012).

La edad de la Formación Mezcala varía desde el Cenomaniano temprano hasta el Maastrichtiano (Alencáster, 1980; Aguilera-Franco, 1995; Estrada-Flores, 1995; Guerrero-Suastegui, 2004). Sin embargo, estudios paleontológicos realizados dentro del área de estudio y zonas aledañas, indican que esta formación, en la cuenca de Pachivia, tiene una edad del Cenomaniano temprano hasta el Turoniano temprano (Guerrero-Suastegui, 2004; Guerrero-Suastegui et al., 2006a). Por otro lado, en la Cuenca de Taxco-Atlixtac, la edad de la Formación Mezcala varía del Cenomaniano tardío al Turoniano tardío (Estrada-Flores, 1995; Fitz-Díaz et al., 2002; Ocampo-Díaz et al., 2002; Rosendo-Brito et al., 2002; Guerrero-Suastegui, 2004; Guerrero-Suastegui et al., 2006a; Figuras 2 y 3 ).

\section{METODOLOGÍA}

El levantamiento de perfiles sedimentológicos-estratigráficos y la cartografía de facies se efectuaron con base en la propuesta de Underwood (1984), modificada por Leverenz (2000). El reconocimiento, descripción e interpretación de las facies se basó en los esquemas de facies de aguas profundas propuestos por Pickering y Hiscott (2016; e. g. facies A2.1). La interpretación del modelo de depósito se realizó considerando la propuesta de abanicos submarinos antiguos de Mutti y Ricci-Lucchi (1972), mientras que los tipos de abanicos submarinos fueron clasificados de acuerdo con Reading y Richards (1994). Los datos de paleocorrientes se colectaron y restauraron con la metodología de Filguera (2010).

\section{RESULTADOS}

\section{Descripción y análisis de facies sedimentarias}

El análisis sedimentológico-estratigráfico permitió documentar cuatro clases de facies, 22 facies sedimentarias agrupadas en ocho asociaciones de facies, las cuales se describen a continuación.

Clase de facies A: Gravas lodosas, lodos gravosos, arenas gravosas, $\geq 5 \%$ de gravas

Facies A1.1: Conglomerados desorganizados. La facies A1.1 está constituida por conglomerados (gránulos a guijarros gruesos) soportados por granos (Figura 4a). Los exoclastos son de calizas, redondeados a subangulosos, que varían de moderadamente a bien clasificados. El espesor de los estratos varía de medianos a gruesos $(\sim 70 \mathrm{~cm})$, con contactos inferiores erosivos y con morfología lenticular y acuñada. Esta facies sobreyace de manera erosiva y subyace de manera concordante a las facies C1.1, C1.2, C2.2, C2.3, D1.1 y D1.2. La facies aflora en las inmediaciones de los poblados de Tecalpulco, Santiago Temixco y Paintla (Figura 3). Las características sedimentológicas permiten interpretar que el proceso de transporte se efectuó por flujos de escombros concentrados de arenas y gravas, donde el mecanismo de depósito se supone que estuvo relacionado con el "congelamiento" ocurrido por la fricción intergranular y la cohesión al disminuir la pendiente de la base (Pickering y Hiscott, 2016).

Facies A1.2: Conglomerados lodosos desorganizados. La facies A1.2 se caracteriza por conglomerados (gránulos a guijarros finos) soportados por una matriz calcárea (Figura $4 \mathrm{~b}$ ). Los clastos son redondeados a subredondeados, compuestos principalmente por fragmentos de extracuenca de caliza y lutita recicladas del sustrato (Figura $4 \mathrm{~b}$ ). El espesor de los estratos varía de delgados a gruesos $(\sim 60 \mathrm{~cm})$, con contactos inferiores y superiores erosivos, en tanto que la morfología de los mismos es tabular y lenticular. Esta facies sobreyace de manera erosiva y concordante a las facies C1.1, C1.2, C2.2, D1.1 y D1.2, aflorando en las inmediaciones de los poblados de Tecalpulco, Santiago Temixco, Atzala y Paintla (Figura 3). La facies A1.2 representa el transporte de sedimentos por flujos de escombro cohesivos (Pickering y Hiscott, 2016).

Facies A1.3: Lodos gravosos desorganizados. La facies A1.3 está constituida por conglomerados (gránulos a guijarros finos) soportados por matriz arenosa-lodosa (Figuras $4 \mathrm{c}$-d). Texturalmente, los clastos son angulosos a subredondeados, variando de pobremente a muy pobremente clasificados. Los clastos son de caliza, arenisca, fragmentos volcánicos de dacita y andesita, lutita y cuarzo. El espesor de los estratos varía de mediano a muy grueso $(\sim 80 \mathrm{~cm})$, con contactos inferiores erosivos con morfología lenticular. Esta facies sobreyace a las facies A2.2, C2.2 y C1.1. Las características sedimentológicas de la facies A1.3 permite interpretarla como un depósito de flujos de lodos cohesivos (flujos de escombros) (Pickering y Hiscott, 2016).

Facies A1.4: Areniscas conglomerádicas a muy gruesas con gradación inversa. La facies A1.4 consiste en areniscas con gradación inversa cíclica. El tamaño de grano varía de arenas medias a gránulos (Figura 4e). Los clastos son subagulosos a subredondeados soportados por una matriz de arenisca de grano muy fino. La composición de los clastos es de caliza, arenisca, lutita, cuarzo, líticos volcánicos y metamórficos y feldespato. La estratificación varía de mediana a muy gruesa $(\sim 60 \mathrm{~cm})$, mostrando niveles amalgamados y contactos rectos y ligeramente erosivos. Esta facies sobreyace y subyace a la facies B1.1, y aflora en las inmediaciones del poblado de Tecalpulco (Figura 3). Las características texturales que presenta la facies A1.4 indican transporte de sedimentos por corrientes turbidíticas de alta densidad, en el que el depósito en masa de los granos de gravas y arenas mezclados por fricción intergranular, produjo la desaceleración del flujo y, por lo tanto, la gradación inversa cíclica (Pickering y Hiscott, 2016).

Facies A2.2: Conglomerados inversamente gradados. La facies A2.2 está conformada por conglomerados con gradación inversa, con un rango del tamaño de grano que varía de arenas muy gruesas a guijarros finos. Los clastos son subredondeados a redondeados, inmersos en una matriz de arenisca fina a media menor a $25 \%$ (Figura $4 \mathrm{f}$ ). Los clastos son de caliza, lutita, arenisca, cuarzo, líticos volcánicos y metamórficos. Los contactos de la facies A2.2 no son muy visibles, pero se infieren por la geometría que presentan, los cuales son altamente erosivos y su morfología lenticular. El espesor de los estratos varía de medianos a gruesos $(\sim 60 \mathrm{~cm})$. Esta facies generalmente subyace de manera concordante a las facies C2.1 o D2.1 (Figura 3). Las características sedimentológicas que presenta la facies A2.2 permiten interpretar un transporte de sedimento por corrientes turbidíticas de alta densidad, donde el mecanismo de depósito fue rápido como parte de un lecho de tracción concentrado de sedimentos (Pickering y Hiscott, 2016). 

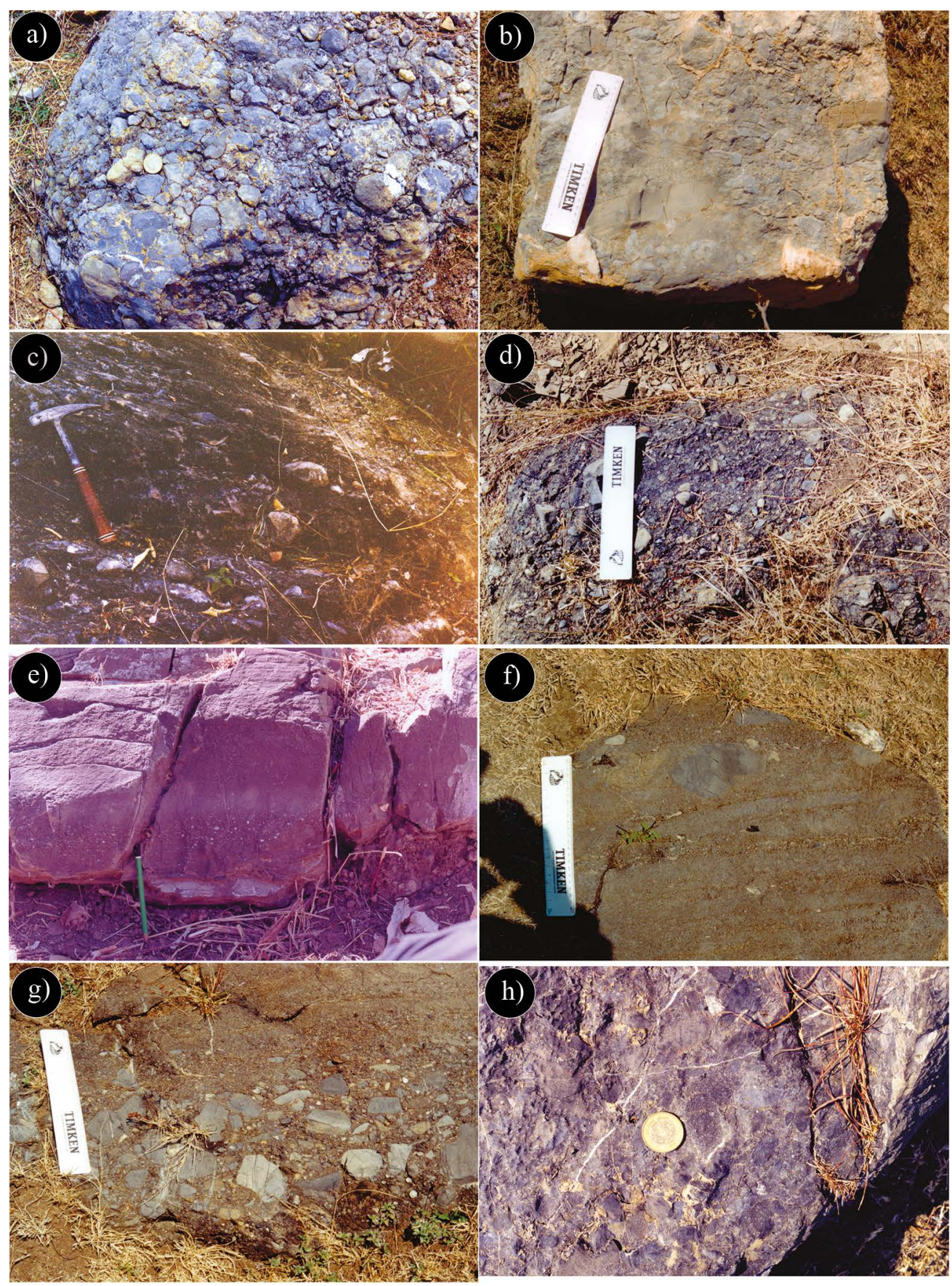

Figura 4. Fotografías de las facies de las clases conglomerádicas: a) conglomerado calcáreo soportado por granos de la facies A1.1; b) conglomerado soportado por matriz calcárea de la facies A1.2; c) y d) conglomerado soportado por matriz arcillo-arenosa con desarrollo de imbricación incipiente de la facies A1.3; e) arenisca de grano muy grueso con gradación inversa cíclica de la facies A1.4; f) conglomerados inversamente gradados con desarrollo de lechos de tracción de la facies A2.2; g) conglomerados normalmente gradados compuestos principalmente por clastos de caliza de la facies A2.3; (h) conglomerados soportados por clastos compuestos por clastos de andesita y caliza de la facies A2.4. La regla mide 15 centímetros.

Facies A2.3: Conglomerados normalmente gradados. La facies A2.3 se caracteriza por mostrar estratos delgados a medianos $(\sim 30 \mathrm{~cm})$ de conglomerados con gradación normal, con algunos niveles de clastos flotados, situados en la parte superior de los depósitos, con el desarrollo de imbricación incipiente (Figura 4g). El tamaño de los clastos varía de guijarros finos a arenas gruesas, soportados por una matriz del tamaño de arenas finas $(<20 \%)$. Los clastos son subangulosos a subredondeados, siendo principalmente de caliza, cuarzo, feldespato, arenisca y lutita. Los contactos son, generalmente, planos y muy rara vez erosivos, con morfología lenticular. La facies A2.3 subyace de manera concordante a las facies C2.2 y sobreyace de manera erosiva a las facies C1.1 y D1.1 (Figura 3). Las características sedimentológicas que presenta la facies A2.3 indican un transporte de sedimentos por corrientes turbidíticas de alta concentración de gravas y arenas, donde el mecanismo de depósito es generado por la suspensión dentro del flujo (Pickering y Hiscott, 2016). 
Facies A2.4: Conglomerados soportados por clastos. La facies A2.4 se caracteriza por conglomerados soportados por clastos, moderadamente a bien clasificados, con un rango en el tamaño de gránulos finos a guijarros finos; los clastos son subangulosos a subredondeados (Figura $4 \mathrm{~h}$ ). Su composición varía según la ubicación: en los afloramientos situados en las inmediaciones de Tecalpulco, Cerro Gordo, Puente Campuzano y Santiago Temixco, los clastos son de caliza, arenisca, lutita, cuarzo, líticos sedimentarios y feldespatos, mientras que en las inmediaciones de Huixtac, los fragmentos son de andesita, feldespato, cuarzo y caliza (Figura 3). El espesor de esta facies varía de estratos gruesos a delgados $(\sim 50 \mathrm{~cm})$. Los contactos son, generalmente, erosivos; sobreyacen y subyacen a las facies C2.3, C1.1, C1.2, D1.1. La ausencia de matriz y las características sedimentológicas permiten interpretar un transporte de sedimentos por corrientes turbidíticas de alta concentración (Pickering y Hiscott, 2016).

Facies A2.6: Conglomerados gradados inversamente-normalmente. La facies A2.6 se caracteriza por conglomerados con gradación inversa en la base de los estratos y gradación normal hacia la cima. El tamaño de grano varía de gránulos finos a guijarros finos, que texturalmente son subangulosos a subredondeados y mal clasificados (Figura 5a). Los clastos son de caliza, lutita, arenisca, cuarzo y feldespato, contenidos dentro de una matriz de arenas finas $(\leq 30 \%)$. El rango de estratificación varía de delgada a gruesa $(\sim 80 \mathrm{~cm})$, con contactos inferiores, erosivos y superiores, planos. Esta facies subyace a las facies C2.1, C2.2, C2.3, C1.1, D1.1 (Figura 3). La asociación de gradación inversa y normal que muestra la facies A2.6 permite interpretar un transporte de sedimentos relacionado con corrientes turbidíticas de alta concentración, donde el mecanismo de depósito se desarrolló por la descarga rápida del sedimento (Pickering y Hiscott, 2016).

Clase de facies B: Arenas ( $\geq 80 \%)$ y gravas $(<5 \%)$

Facies B1.1: Areniscas masivas con clastos flotados. La facies B1.1 se caracteriza por la ausencia de estructuras sedimentarias de carácter interno, sin embargo, presenta clastos flotados dentro de una matriz arenosa de grano medio a grueso (Figura $5 b$ ). El tamaño de los clastos flotados varía de gránulos finos a guijarros finos, siendo principalmente exoclastos calcáreos o intraclastos de lutita. El espesor de los estratos es delgado a muy grueso $(\sim 70 \mathrm{~cm})$, con contactos planos o ligeramente ondulados, localmente intercalados con pequeños horizontes de lutita (mud drapes), con espesores no mayores de $20 \mathrm{~cm}$. Esta facies aflora en las inmediaciones del poblado de Tecalpulco y Taxco el Viejo, donde la sobreyacen las facies C2.1, C1.1 y B1.1, B1.2 (Figura 3). La facies B1.1 representa el transporte de sedimentos por corrientes turbidíticas de alta concentración, donde el mecanismo de transporte está relacionado con el depósito rápido de masas (Pickering y Hiscott, 2016).

Facies B1.2: Areniscas con estratificación lenticular. La facies B1.2 está constituida por areniscas de grano medio a grueso con desarrollo de estratificación lenticular (Figura 5c). La estratificación es delgada a mediana, exhibiendo un arreglo interno de gradación normal, con contactos generalmente planos. Esta facies subyace a las facies B1.1, aflora en las inmediaciones del poblado de Tecalpulco (Figura 3). La estratificación lenticular sugiere condiciones relacionadas a un depósito rápido en masa (Pickering y Hiscott, 2016).

Facies B2.2: Areniscas con estratificación cruzada. La facies B2.2 se caracteriza por areniscas de grano grueso a gránulos con estratificación o laminación cruzada de tipo tangencial y plana (Figura 5d). La estratificación varía de delgada a gruesa $(\sim 60 \mathrm{~cm})$. Los contactos son generalmente planos, o ligeramente erosivos cuando se encuentran intercaladas con lutita en una relación de $80 / 20 \%$. La presencia de estratificación cruzada y/o laminación cruzada de tipo plana permite interpretar que el mecanismo de transporte de sedimentos de la facies B2.2 se efectuó por corrientes turbidíticas diluidas o por fuertes corrientes dentro de canales confinados, donde el mecanismo de depósito se desarrolló por medio de avalanchas o de suspensión intermitente; ambos casos son generados por la dispersión de los granos. Este aporte continuo favorece la migración de dunas y rizaduras (Pickering y Hiscott, 2016).

\section{Clase de facies C: Pares de arenas-lodos y arenas lodosas}

(20-80\% de arenas, $<80 \%$ de lodos más limos)

Facies C2.1, C2.2, C2.3 y C2.4: Areniscas con estratificación muy delgada a gruesa. Las facies C2.1, C2.2 y C2.3 consisten de grandes proporciones de arenisca de grano fino a muy grueso intercaladas con lutita en relaciones variables de $50-80 \%$ de arenisca y $20-50 \%$ de lutita. La característica principal de estas facies es la presencia completa o parcial de la secuencia Bouma clásica y sus variaciones (e. g. Tabcde, Tabc y Ta; Figuras 5e-5f; Pickering y Hiscott, 2016). Grandes cantidades de clastos flotados de lutita de origen intracuenca están incluidos en los estratos de arenisca. En la base de los estratos arenosos es común observar surcos de erosión y estructuras generadas por arrastre, saltación y desgaste por fricción de partículas (Figuras 5g-5h). El espesor de los estratos de arenisca varía de muy delgada a gruesa $(\sim 45 \mathrm{~cm})$, mostrando contactos generalmente planos, y localmente erosivos. Las facies C2.1, C2.1, C2.3 y C2.4 sobreyacen y subyacen de manera concordante a las facies C1.1, C1.2, D2.1, D2.2, y de manera particular subyacen de modo erosivo a la facies A2.2. Esta facies se distribuye en toda el área de estudio (Figura 3). La presencia de las estructuras sedimentarias que conforman la secuencia Bouma y sus variaciones, más las relaciones de arenisca/lutita, permiten interpretar que las facies C2.1, C2.2, C2.3 y C2.4 fueron generadas por corrientes turbidíticas de alta y baja concentración, donde cada secuencia Bouma completa o incompleta está relacionada con la dilución y la disminución del régimen de flujo de corrientes turbidíticas episódicas (Bouma, 1962; Pickering y Hiscott, 2016).

Facies C1.1: Areniscas con gradación normal y laminaciones paralelas o convoluta. La facies C1.1 se caracteriza por areniscas de grano fino a grueso que puede presentar de manera local gradación normal, laminación paralela o convoluta, en estratos delgados a medianos ( $20 \mathrm{~cm}$; Figura $6 \mathrm{a})$. Los contactos son generalmente planos y rara vez ondulados. La relación de arenisca y lutita es de $30-70 \%$. El espesor de los estratos de lutita es muy delgado a mediano $(\sim 15 \mathrm{~cm})$, con abundantes laminaciones paralelas. Esta facies sobreyace y subyace a las facies C2.1, C2.2 y C2.3 (Figura 3). Las características sedimentológicas de la facies C1.1 indican un transporte de sedimentos por corrientes turbidíticas de alta densidad, ricas en lodos o flujos de escombros ricos en arenas y/o flujos de lodos, donde el mecanismo de depósito fue rápido y en masa (Pickering y Hiscott, 2016).

Facies C1.2: Areniscas con laminaciones cruzadas. La facies C1.2 se caracteriza por arenisca de grano fino a medio con laminaciones cruzadas planas, intercaladas con niveles delgados a medianos de lutita en proporciones de 70\%-30\%. La estratificación varía de delgada a mediana $(\sim 20 \mathrm{~cm})$. Los contactos son, generalmente, ondulados o ligeramente erosivos. Esta facies aflora en gran parte del área de estudio, donde sobreyace y subyace a las facies de areniscas lodosas (C2.1, C2.2 y C2.3) o a la facies de lutita arenosa (D1 y D2; Figura 3). Las características sedimentológicas de la facies C1.2 permite interpretar un transporte de sedimentos por corrientes de fondo oceánico, donde el mecanismo de depósito fue por segregación grano a grano, asociado con el depósito posterior de arenas y lodos (Pickering y Hiscott, 2016). 

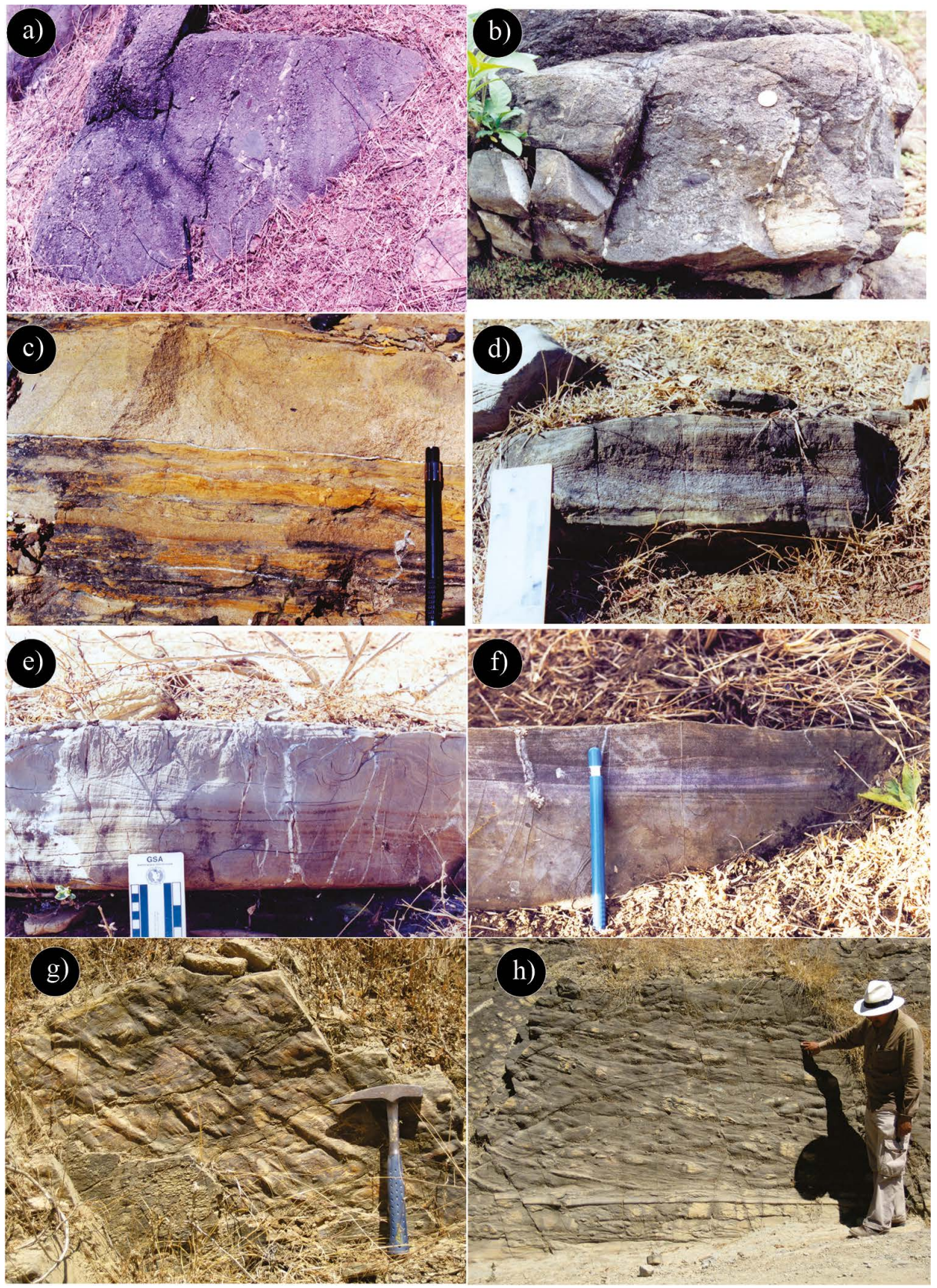

Figura 5. Fotografías de las facies de las clases A, $\mathrm{B}$ y C: a) conglomerados normal a inversamente gradados de la facies A2.6; la base del estrato se sitúa a la izquierda de la fotografía; b) areniscas masivas con clastos flotados de lutita de la facies B1.1; c) areniscas de grano medio con estratificación lenticular de areniscas de grano grueso de la facies B1.2; d) areniscas con estratificación cruzada generada por la migración de dunas de corriente de la facies B2.2; e) areniscas con la secuencia Bouma completa, "Tabcde", de la facies $\mathrm{C} 2.1 ; \mathrm{f})$ areniscas con la presencia parcial de la secuencia Bouma, "Tbcde", característica de la facies C2.2; g) y h) estructuras de flujo, "flautas" y surcos de erosión asociadas con estructuras por arrastre y saltación de partícula de las facies C2.2 y C2.3, respectivamente.
Clase de facies D: Limos, limos lodosos y pares de limos y lodos ( $>80 \%$ de lodos, $\geq 40 \%$ de limos, $0-2 \%$ de arenas)

Facies D1.1: Lutitas arenosas laminadas. La facies D1.1 está compuesta por areniscas de grano fino a mediano con laminaciones paralelas, intercaladas con lutita en una relación de 30\% de arenisca por $70 \%$ de lutita. El espesor de los estratos de arenisca varía de muy delgada a gruesa (Figura $6 \mathrm{~b}$ ), mientras que los estratos de lutita varían de delgada a mediana, con secuencias laminadas hasta estratificación muy delgada. Los contactos entre los niveles de lutita y arenisca son, generalmente, paralelos, presentándose también ondulados por la presencia de moldes de carga y en algunos casos se presentan surcos de erosión en la base de los estratos arenosos. La facies D1.1 sobreyace y subyace a las facies C1.1, C2.3, D2.1 y D1.2, de manera concordante, y subyace de forma erosiva o concordante a la facies A (Figura 3). La facies D1.1 se interpreta como el resultado de sedimentos transpor- tados por corrientes turbidíticas de alta concentración ricas en limo o bien por flujos de escombros lodosos altamente fluidos, donde el mecanismo de depósito en ambos casos es el congelamiento friccional (Pickering y Hiscott, 2016).

Facies D1.2 y D2.2: Lutita arenosa masiva. Las facies D1.2 y D2.2 se caracterizan por intercalaciones de lutita-limolita $(\sim 80 \%)$ y arenisca ( 20\%; Figuras 6c y 6e). Los estratos de lutita exhiben laminaciones paralelas en la base de los estratos, con espesores delgados a gruesos $(\sim 60 \mathrm{~cm})$. Los estratos arenosos tienen espesores gruesos, con estratificación delgada a mediana $(\sim 10 \mathrm{~cm})$. Los contactos son, generalmente, ondulados (arenisca/lutita) y raramente erosivos, pero entre la limolita y la lutita son planos y gradacionales. Las facies D1.2 y D2.2 sobreyacen y subyacen a las facies C1, C2, D1 y D2. Las características sedimentológicas que exhiben las facies D1.2 y D2.2 indican un transporte de sedimento por corrientes turbidíticas de alta concentración 

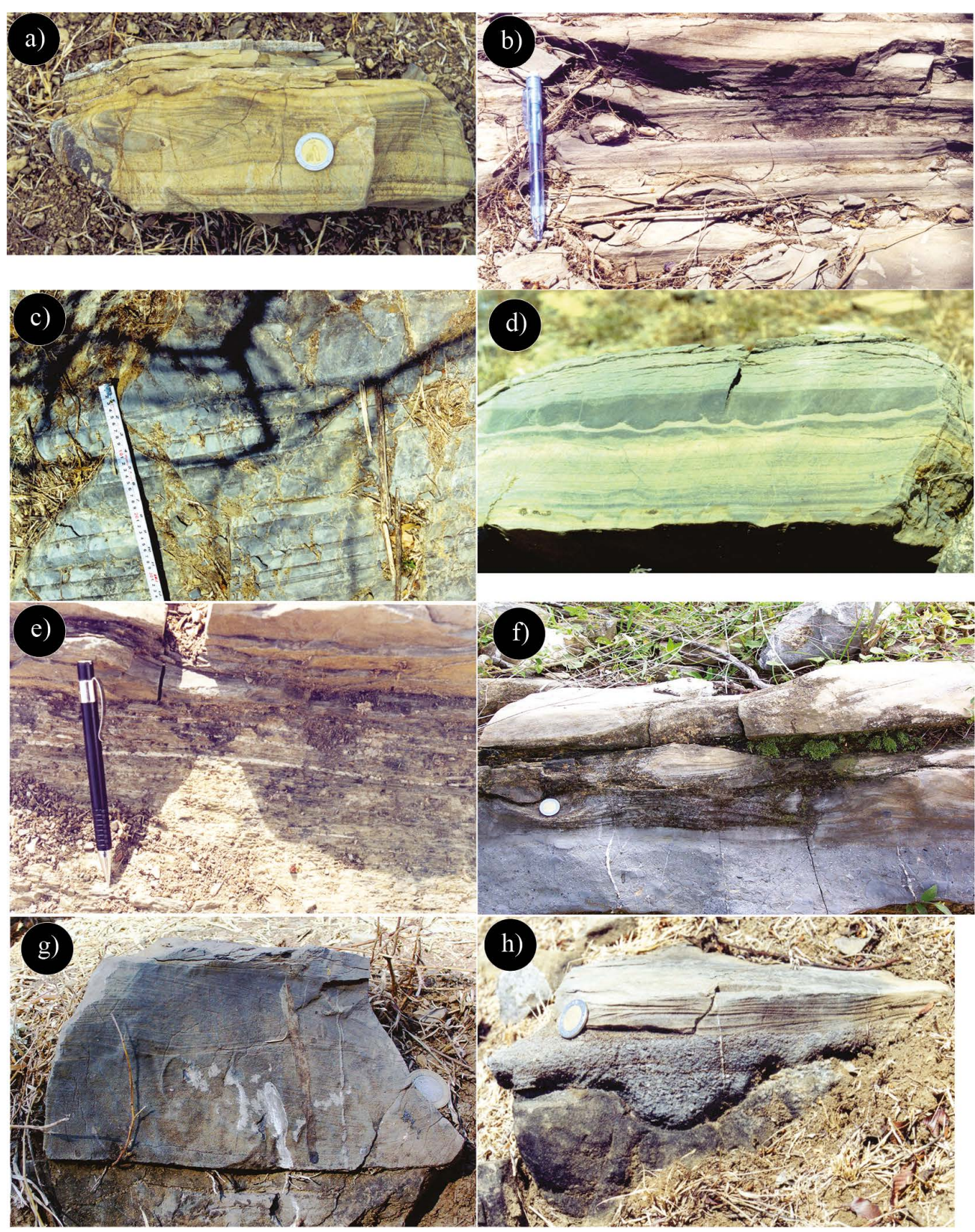

Figura 6. Fotografías de las clases C, D y depósitos no turbidíticos "DNT": a) areniscas de la facies C1.1, caracterizada por laminaciones paralelas-laminación convoluta-laminaciones paralelas; b) facies de lutitas arenosas laminadas de la facies D1.1; c) lutitas y limolitas gradadas de la facies D1.2; d) lutitas y limolitas gradadas con estructuras de deformación de "moldes de carga y estructuras en flama" de la facies D2.2; e) lutitas, limolitas y estratos muy delgados de arenisca fina de la facies D2.1;f) depósitos asociados a turbiditas que muestran una base erosiva constituida por conglomerados residuales bioclásticos, cubiertos por estratificación de tipo swaley y hummocky; g) sucesión de estratificación cruzada de tipo swaley y hummoky caracterizada por mostrar bajo ángulo dentro de las sucesiones profundas; y h) caliza de tipo grainstone bioclástica de las facies DNT con bases muy erosivas con surcos de erosión, a los que cubren laminaciones cruzadas de bajo ángulo.

en fracción de lodos, o por corrientes turbidíticas de baja densidad. El mecanismo de depósito está relacionado con la suspensión de los granos de limo y arcilla, vinculados con la clasificación del tamaño de grano dentro de las subcapas viscosas, o por la suspensión grano a grano (sólo para turbiditas), seguida por transporte de tracción de los limos en suspensión (Pickering y Hiscott, 2016).

Facies D2.1: Limolita-lutita arenosa. La facies D2.1 se caracteriza por sucesiones alternadas de limolita, lutita (90\%) y arenisca (10\%; Figura 6d). Los estratos de limolita y lutita varían de medianos a gruesos $(\sim 70 \mathrm{~cm})$, con gradación normal y laminaciones paralelas. La secuencia de arenisca tiene un espesor muy grueso pero con capas muy delgadas a medianas $(\sim 15 \mathrm{~cm})$. Los contactos son planos y, localmente, ondulados. Esta facies sobreyace y subyace de manera concordante a la clase de facies C2, C1, D1 y D2 (Figura 3). La facies D2.1 representa el transporte de sedimentos por corrientes turbidíticas de baja concentración, donde el mecanismo de depósito se realiza grano a grano, seguida por transporte de tracción sobre la base de los estratos, lo que favorece al desarrollo de las laminaciones paralelas (Pickering y Hiscott, 2016).

Facies DNT: Depósitos no turbidíticos. La facies DNT se caracteriza por presentar estratos de caliza de tipo grainstone con un tamaño de 
grano de guijarros a areniscas finas, mostrando depósitos residuales en la base de los estratos, estratificación cruzada de tipo "swaley" y hummocky" y laminaciones paralelas en la cima. El rango de estratificación varía de muy delgada a gruesa $(\sim 30 \mathrm{~cm})$. Los clastos son subangulosos a subredondeados, siendo de caliza, lutita y bioclastos de crinoides, gasterópodos y amonites, que se encuentran en una matriz calcáreoarcillosa. La facies DNT también puede estar presente de manera independiente, como una caliza de tipo grainstone de bioclastos y con estratificación cruzada de tipo swaley-hummocky; esta última estructura está asociada con laminaciones paralelas (Figura 6f-6h). Los contactos internos tanto en la base como en la cima, fueron fuertemente erosionados y exhiben morfología lenticular. Esta facies subyace a la facies de areniscas lodosas ( $\mathrm{C} 1$ y C2), donde los contactos son esencialmente erosivos; esta facies sobreyace, de forma erosiva, a la sucesión terrígenacarbonatada de la Formación Agua Nueva. Sin embargo, se tiene que señalar que la caliza de tipo grainstone de bioclastos, se presenta de manera aislada dentro de las facies D1, D2.1 y C2.3 (Figura 3), mostrando contactos inferiores erosivos y contactos superiores planos. La facies DNT se interpreta como el resultado de la erosión que producen corrientes turbidíticas episódicas, relacionadas con procesos de alta energía, ocurridas tanto en la línea de costa como en la cuenca (Dott y Bourgeois, 1982; Brenchely, 1985; Mulder et al. 2009).

\section{Asociaciones de facies}

El reconocimiento de las clases de facies y de las facies permite proponer ocho asociaciones de facies que documentan distintas partes de abanicos submarinos y depósitos relacionados con turbiditas dentro de la cuenca de Taxco-Atlixtac; a continuación, se describen:

\section{Asociación de facies 1 (AF1)}

La AF1 está formada por las facies A1.3, A2.2, A2.4, A2.3 y A2.6 (Figura 7). Típicamente estos depósitos presentan bases erosivas y abruptas, morfologías lenticulares, geometría convexa (Figura 7) y cimas que se adelgazan hacia la cima. Estos depósitos son conglomerados bien estratificados o gradados, y en menor frecuencia no gradados y desorganizados. Internamente, las superficies de erosión comúnmente forman horizontes de clastos imbricados. Esta asociación de facies se interpreta como la etapa de relleno de canales submarinos, relacionados con el depósito principalmente de corrientes turbidíticas y flujos de densidad concentrados (Figura 7). La asociación de facies 1 sobreyace y cambia lateralmente a las asociaciones AF4 y 5 . Pendiente abajo del sistema de depósito, esta asociación de facies es lateralmente más extensa y forma los depósitos de la transición lóbulo-canal y de lóbulo cercano cuando los sistemas no están confinados (Figura 7).

\section{Asociación de facies 2 (AF2)}

La AF2 está conformada por las facies A2.4, A2.3, A2.2 C2.3, C1.1 y D2.1 (Figura 7). Los estratos individuales presentan cimas y bases abruptas, y típicamente exhiben morfologías lenticulares con poca continuidad lateral. La asociación AF2 sobreyace concordantemente y cambia lateralmente con las asociaciones AF1 y AF3. La asociación AF2 se interpreta como depósitos de intercanal o de desborde de canal, tanto en la parte lejana del abanico interno como en la parte cercana del abanico medio, según el modelo de Mutti y Ricci-Lucchi (1972; Figura 9).

\section{Asociación de facies 3 (AF3)}

La asociación AF3 está conformada por las facies A1.4, A2.4, B1.1, B2.2, C2.1, D1.1 y D2.2 (Figura 7). Las facies conglomerádicas y arenosas exhiben gradación normal e inversa, y normal-inversa cíclica con abundantes clastos flotados de diversos tamaños, laminaciones paralelas de régimen de flujo superior que lateralmente son discontinuas.
Los estratos individuales tienen cimas y bases abruptas y paralelas y, generalmente, exhiben surcos de erosión. La clase de facies D muestra laminaciones paralelas con estratificación delgada que lateralmente son discontinuas; comúnmente, se encuentran intercaladas con la clase de facies B. La asociación AF3 se interpreta como depósitos de la transición lóbulo-canal, situados dentro del abanico medio tanto en su parte cercana como en su parte lejana (Mutti y Normark, 1987) o bien, como depósitos de relleno posterior de los canales submarinos.

\section{Asociación de facies 4 (AF4)}

La asociación AF4 está conformada por las facies C1.1, D1.1, D1.2 y D2.2), dispuestas en sucesiones que disminuyen el espesor de los estratos con gradación normal. Individualmente, los estratos presentan cimas y bases erosivas que comúnmente están asociados con surcos de erosión y estructuras de arrastre y saltación de partículas. La asociación AF4 se interpreta como depósitos de corrientes turbidíticas y representa la fase del relleno de la formación del canal o depósitos de canal abandonado (Figura 7). La cartografía de las facies sugiere que, con el relleno, los flujos derivaron principalmente de los conductos situados en las áreas marginales cuando los canales estaban colmados. La asociación AF4 se localiza estratigráficamente sobre las asociaciones AF1 y AF2, subyaciendo a las asociaciones AF1, 2 y 3, pero también puede ocurrir adyacente a éstas.

Asociación de facies 5 (AF5)

La asociación AF5 está constituida por las facies B1.1, C2.1, C2.2, C2.3, C1.1, C2.2 y D1.1 (Figura 8), que inicia con areniscas con gradación normal en áreas más cercanas a la fuente de sedimentos, mientras que en las partes más distantes cambia lateralmente a areniscas con laminaciones paralelas de régimen de flujo inferior. La estratificación es delgada a gruesa, lateralmente continua, dispuesta dentro de sucesiones de crecimiento progresivo. Los estratos presentan bases y cimas erosivas y paralelas, típicamente asociadas con pequeños surcos de erosión y estructuras de arrastre y saltación de partículas. La asociación AF5 se interpreta como el depósito de lóbulos de tipo plano (Galloway y Hobday, 1996), tanto su parte cercana como la distante; éstos se sitúan dentro del abanico medio, de acuerdo al modelo de Mutti y Ricci-Lucchi (1972; Figura 8). La asociación AF5 sobreyace concordantemente a las asociaciones AF5, 7 y 8 , y subyace de manera erosiva a las asociaciones $\mathrm{AF} 1,2,3$ y 8 , cambiando lateralmente a la asociación AF3.

\section{Asociación de facies 6 (AF6)}

La asociación AF6 está conformada por las facies C1.1, D1.1, D1.2 y D2.2. Típicamente, estos depósitos muestran bases erosivas y cimas con gradación normal; son continuos lateralmente y tienen morfología tabular. Comúnmente, estos depósitos se presentan como tríos o pares litológicos: los primeros se componen de lutita y limolita laminadas o masivas en la base, que gradúan a arenisca con gradación normal y laminaciones paralelas. En contraste, los pares no presentan los estratos arenosos. La asociación AF6 se interpreta como depósitos de planicie de cuenca y lóbulo distante que resultó de corrientes turbidíticas de baja concentración, y ocurre estratigráficamente por encima de las asociaciones AF5 y AF7, o bien cambian lateralmente a las mismas; también se encuentran bajo las asociaciones AF2 y AF3.

\section{Asociación de facies 7 (AF7)}

La asociación AF7 está constituida por las facies A1.1 y A1.2; muestra estratificación delgada a gruesa que se acuña lateralmente y con morfología lenticular. Típicamente, estos depósitos presentan bases y cimas erosivas, aflorando de manera aislada en el centro de la cuenca. La asociación AF7 sobreyace de manera erosiva y subyace de 


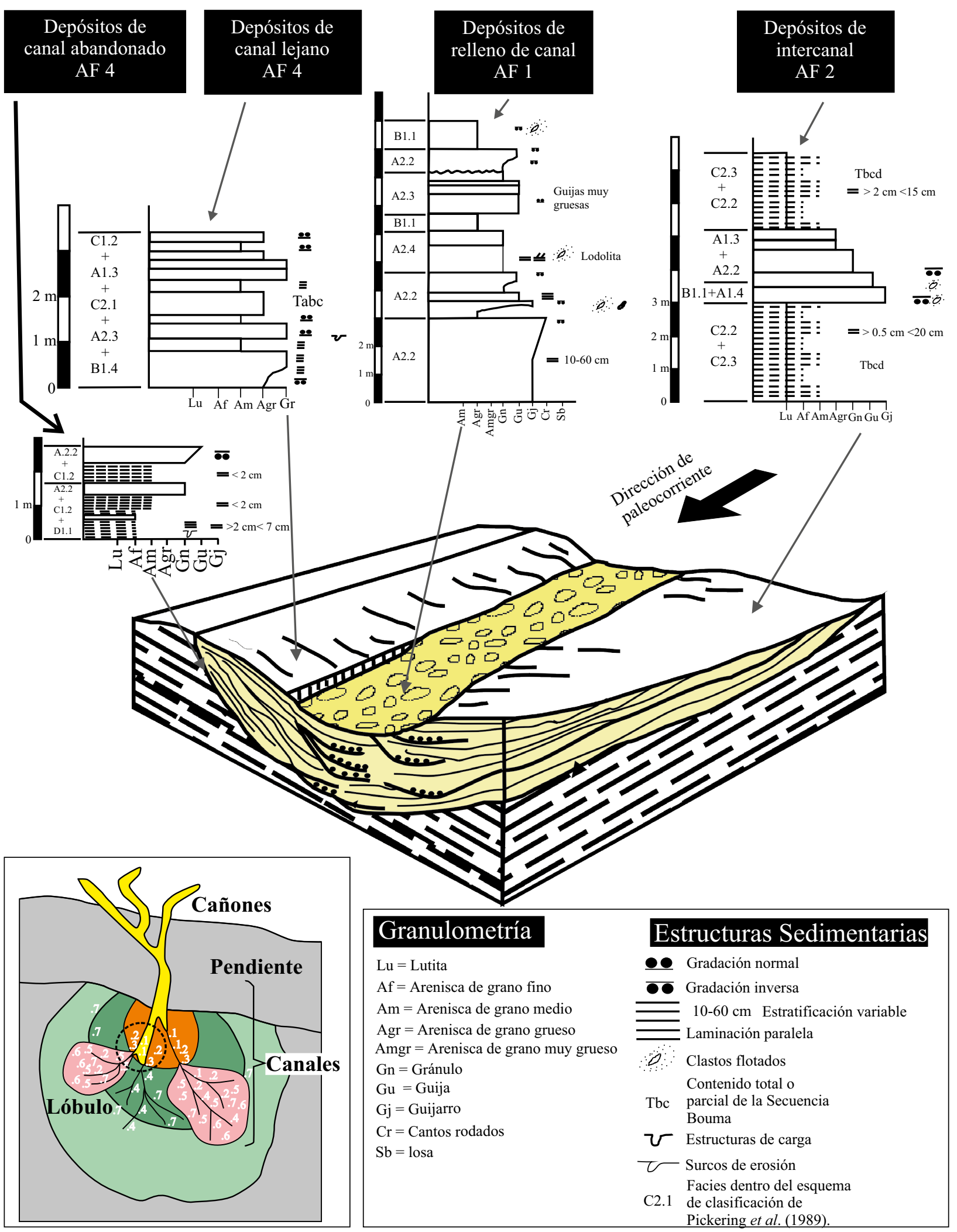

Figura 7. Interpretación sedimentológica de las asociaciones de facies 1, 2, 3 y 4, con base en las diferentes columnas sedimentológicas-estratigráficas medidas en el área de estudio. Modelo del canal submarino tomado de Pickering y Hiscott (2016). Modelo de abanicos submarinos antiguos tomado de Mutti y Ricci-Luchi (1972). El círculo en línea punteada indica la posición de los canales documentados. Los números 1, 2, 3, 4, 5, 6, y 7 hacen referencia a las diferentes asociaciones de facies documentadas en este trabajo. 
manera concordante a las asociaciones AF5 y AF6. Esta asociación de facies se interpreta como un depósito de flujos de escombros altamente cohesivos que evolucionaron a flujos granulares por la pérdida de material fino, derivados posiblemente de la plataforma durante un tiempo de mucha exposición; también representa un límite de secuencia entre diferentes eventos de sedimentación, lo cual se discute más adelante.

\section{Asociación de facies 8 (AF8)}

La asociación AF8 está constituida por caliza de tipo grainstone de bioclastos con estratificación cruzada de bajo ángulo de tipo swaley y hummocky; tiene estratificación delgada a gruesa que se acuña lateralmente, con morfología lenticular (Facies DNT). Típicamente, estos depósitos presentan bases y cimas erosivas, y muestran gradación normal asociada a las superficies de erosión. Comúnmente, estos depósitos son pares o tríos litológicos con el desarrollo de depósitos residuales de conglomerados bien redondeados que gradúan a estratificación cruzada de tipo swaley, a estratificación cruzada de tipo hummocky y a laminaciones paralelas. Los pares litológicos no presentan gravas residuales basales, mostrando únicamente estratificación cruzada de tipo swaley y hummocky, y laminaciones paralelas. La asociación AF8 sobreyace de manera erosiva a los depósitos carbonatados de las formaciones Morelos y Agua Nueva, y a las asociaciones AF5 y AF6, y subyace de manera concordante a las asociaciones AF3, 4 y 5 . La cartografía de facies muestra que la asociación AF7 se distribuye en los límites de la sedimentación clástica-carbonatada, delimitando diversos sistemas de abanicos submarinos, lo cual se discute más adelante.

Estos depósitos representan eventos de alta energía, localizados al borde de la plataforma o bien dentro del fondo marino. La base de estos depósitos comúnmente representa discontinuidades en el registro estratigráfico.

\section{DISCUSIÓN}

Síntesis de la distribución facies y dominios de sedimentación

El análisis sedimentológico, la distribución de facies, el análisis de datos de paleocorrientes, así como los mapas de relación areniscas/ lodos y de la información paleontológica documentada por EstradaFlores (1995), Fitz-Díaz et al. (2002), Ocampo-Díaz et al. (2002), Rosendo-Brito et al. (2002) y Guerrero-Suastegui (2004), permite
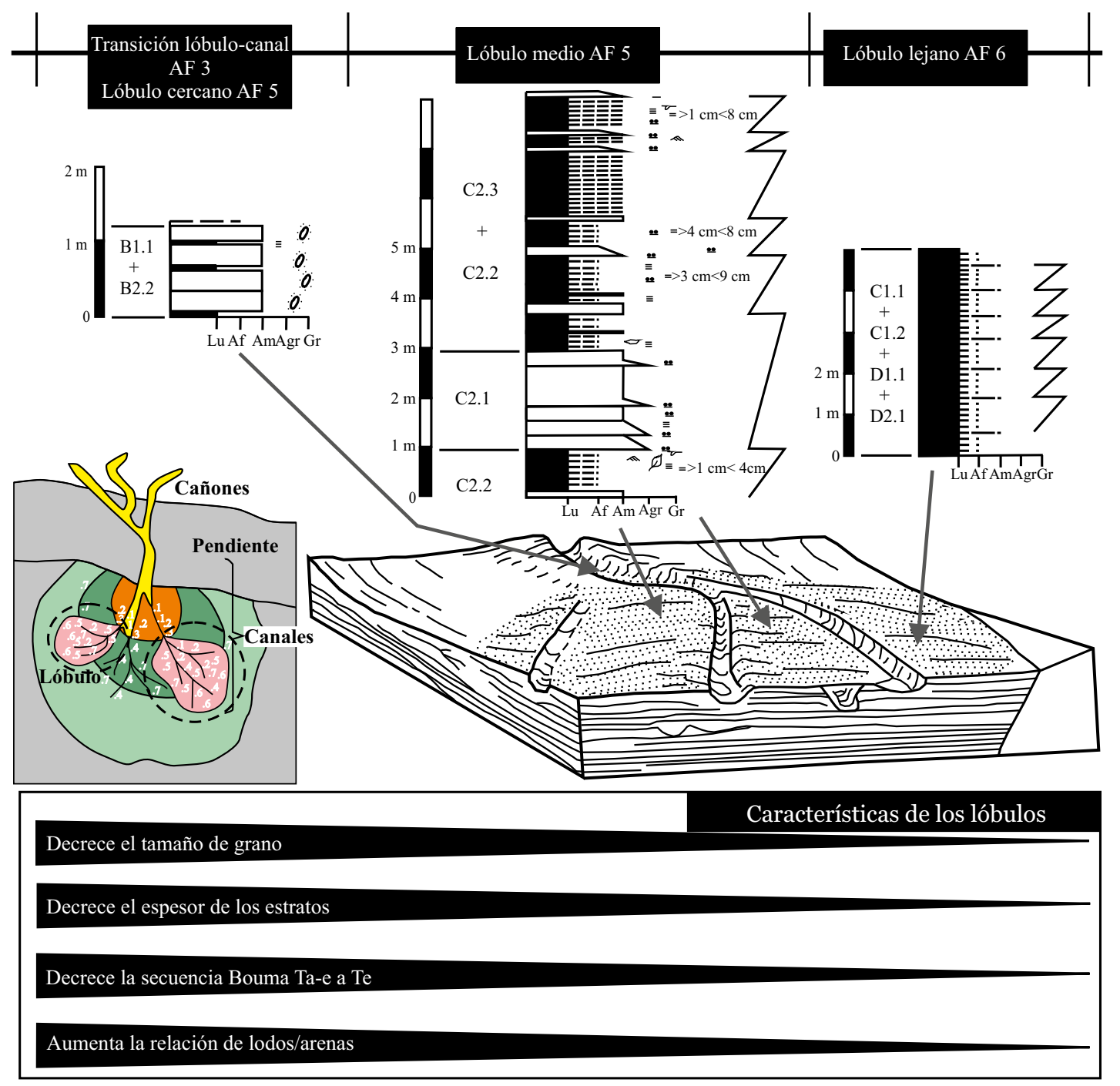

Figura 8. Interpretación sedimentológica de las asociaciones de facies 3, 5 y 6. Modelo del lóbulo tomado de Galloway y Hodbay (1996). Modelo de abanicos submarinos antiguos tomada de Mutti y Ricci-Luchi (1972). El círculo en línea punteada denota la posición de los sistemas documentados dentro del modelo de abanico submarino. Los números 1, 2, 3, 4, 5, 6, y 7 hacen referencia a las diferentes asociaciones de facies documentadas en este trabajo. 
distinguir dos dominios de sedimentación principales. En orden cronoestratigráfico, éstos son: Huixtac-Ojo de Agua y Cerro Gordo-Taxco el Viejo (Figuras 9, 10 y 11; Tabla 1). El dominio de Huixtac-Ojo de Agua está constituido por tres sucesiones sedimentarias profundas (SSP1-3), en tanto que el dominio de Cerro Gordo-Taxco el Viejo, solamente incluye dos sucesiones sedimentarias profundas (SSP-2 y SSP-3). Las sucesiones SSP-1 y SSP-2 se encuentran delimitadas por los depósitos no turbidíticos, en tanto que la sucesión SSP-3 está delimitada por la facies A1.1, en ambos dominios de sedimentación (Figura 9).

\section{Características del dominio de Huixtac-Ojo de Agua (Cenomaniano temprano-Turoniano tardío)}

Agua se caracteriza por una abundancia de las facies C y D, con escasa presencia de la facies B (Figuras 9 y 10). Las facies C y D se presentan en sucesiones de crecimiento frontal progresivo y de acumulación vertical. Estas facies se interpretan como depósitos de lóbulo de depósito con morfología radial y depósitos de desborde de canal (overbank). La sedimentación ocurrió dentro del abanico medio, en su parte próxima-distante (Figura 10), y como depósitos de intercanal, situados dentro del abanico interno en su parte mediadistante. La distribución de la sedimentación tiene direcciones dominantes desde SE30 ${ }^{\circ}$ hasta $\mathrm{SE} 85^{\circ}$ (Figura 10). Por otro lado, la facies $\mathrm{B}$, exhibe sucesiones acumuladas verticalmente que se interpretan como depósitos de canal dentro del abanico interno, desde su parte distante y hasta el abanico medio (AF1; Figura 10; Tabla 1). Las direcciones de los surcos de erosión denotan direcciones de transporte de sedimento hacia el SE65 $5^{\circ}$ La edad documentada de la sucesión SSP-1 es del Cenomaniano temprano como lo determina la asociación faunística de Stamiosphaera sphaerica, Stamiophaerica conoidea, Pitonella ovalis y Pitonella trejo (Estrada-Flores, 1995; Figura 9). La sucesión SSP-2 se caracteriza por secuencias de crecimiento frontal progresivo conformadas por las facies $\mathrm{C}, \mathrm{D}$ y escasa $\mathrm{B}$, más sucesiones de acumulación vertical constituidas por las facies $A, B, C$ y D (Figuras 9 y 10). Las sucesiones de crecimiento frontal representan depósitos de lóbulo alargado con direcciones dispersión de sedimentos desde $\mathrm{NE} 10^{\circ}$ hasta $\mathrm{NE} 60^{\circ}$ (Figura 10). Las sucesiones de acumulación vertical representan depósitos de canales de tipo mixto y de depósito con moderada sinuosidad, incluidos dentro del abanico interno en

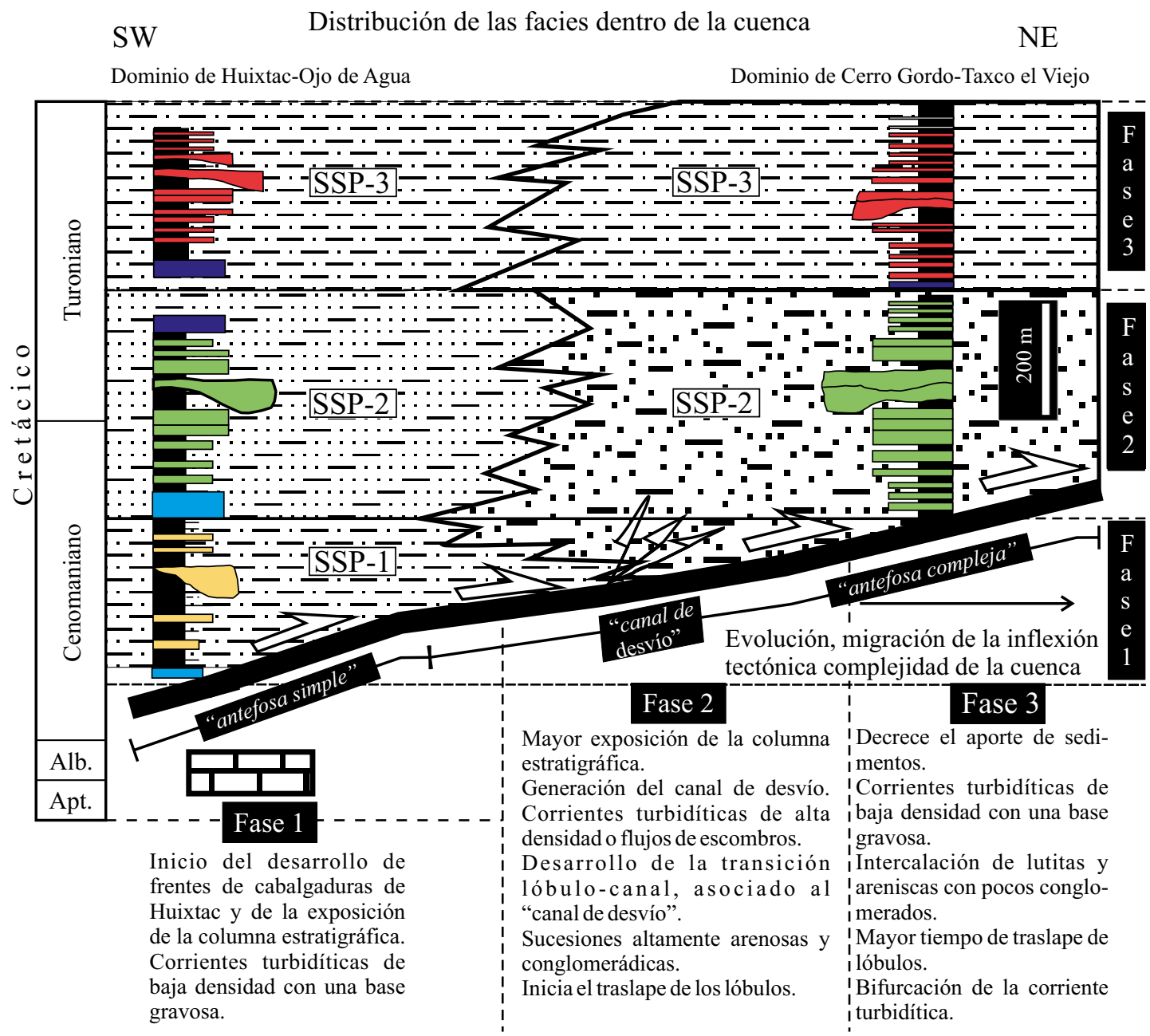

Figura 9. Columnas litoestratigráficas que sintetizan la evolución de los complejos turbidíticos de Huixtac-Ojo de Agua y Cerro Gordo-Taxco el Viejo. Nótese que también se marcan, en la parte inferior de la figura, los diferentes eventos que les dieron origen. Los recuadros en gris denotan los depósitos asociados a turbiditas, interpretados en este trabajo como discontinuidades entre los diferentes tipos de abanicos submarinos, documentados en este trabajo. SSP-1= Sucesión Sedimentaria 1, SSP-2 = Sucesión Sedimentaria 2 y SSP-3= Sucesión Sedimentaria 3. Nota: Las secciones condensadas de cada uno de los dominios de sedimentación, se elaboraron con base en el levantamiento y análisis de 250 perfiles sedimentológicos detallados documentados por Ocampo-Díaz (2004). Los recuadros en color azul claro representan los depósitos no turbidíticos; los recuadros en color azul marino denotan los depósitos de conglomerados resedimentados de la facies A1.1, usados en este trabajo como discontinuidades entre cada una de las sucesiones sedimentarias profundas. 


\begin{tabular}{|c|c|c|c|}
\hline \multicolumn{4}{|c|}{ Explicación } \\
\hline Granulometría & $\begin{array}{l}\mathrm{Cr}=\text { Cantos rodados } \\
\mathrm{Sb}=\text { losa }\end{array}$ & Tbc & $\begin{array}{l}\text { Contenido total o } \\
\text { parcial de la Secuencia } \\
\text { Bouma }\end{array}$ \\
\hline $\begin{array}{l}\mathrm{Lu}=\text { Lutita } \\
\mathrm{Af}=\text { Arenisca de grano fino }\end{array}$ & Estructuras Sedimentarias & v & Estructuras de carga \\
\hline $\mathrm{Am}=$ Arenisca de grano medio & 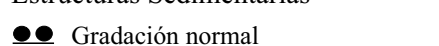 & $\tau$ & Surcos de erosión \\
\hline Agr $=$ Arenisca de grano grueso & Gradación inversa & $C 21$ & Facies dentro del esquema \\
\hline $\begin{array}{l}\text { Amgr = Arenisca de grano muy grueso } \\
\text { Gn }=\text { Granulos }\end{array}$ & $\bar{\equiv} 10-60 \mathrm{~cm}$ Estratificación variable & & $\begin{array}{l}\text { de clasificación de } \\
\text { Pickering et al., } 1989 .\end{array}$ \\
\hline $\mathrm{Gu}=$ Guijas & $\overline{\bar{\ddots}}$ Laminación paralela & 1.0 & Relación de areniscas \\
\hline Gj = Guijarros & $2 \quad$ Clastos flotados & & lutitas \\
\hline
\end{tabular}

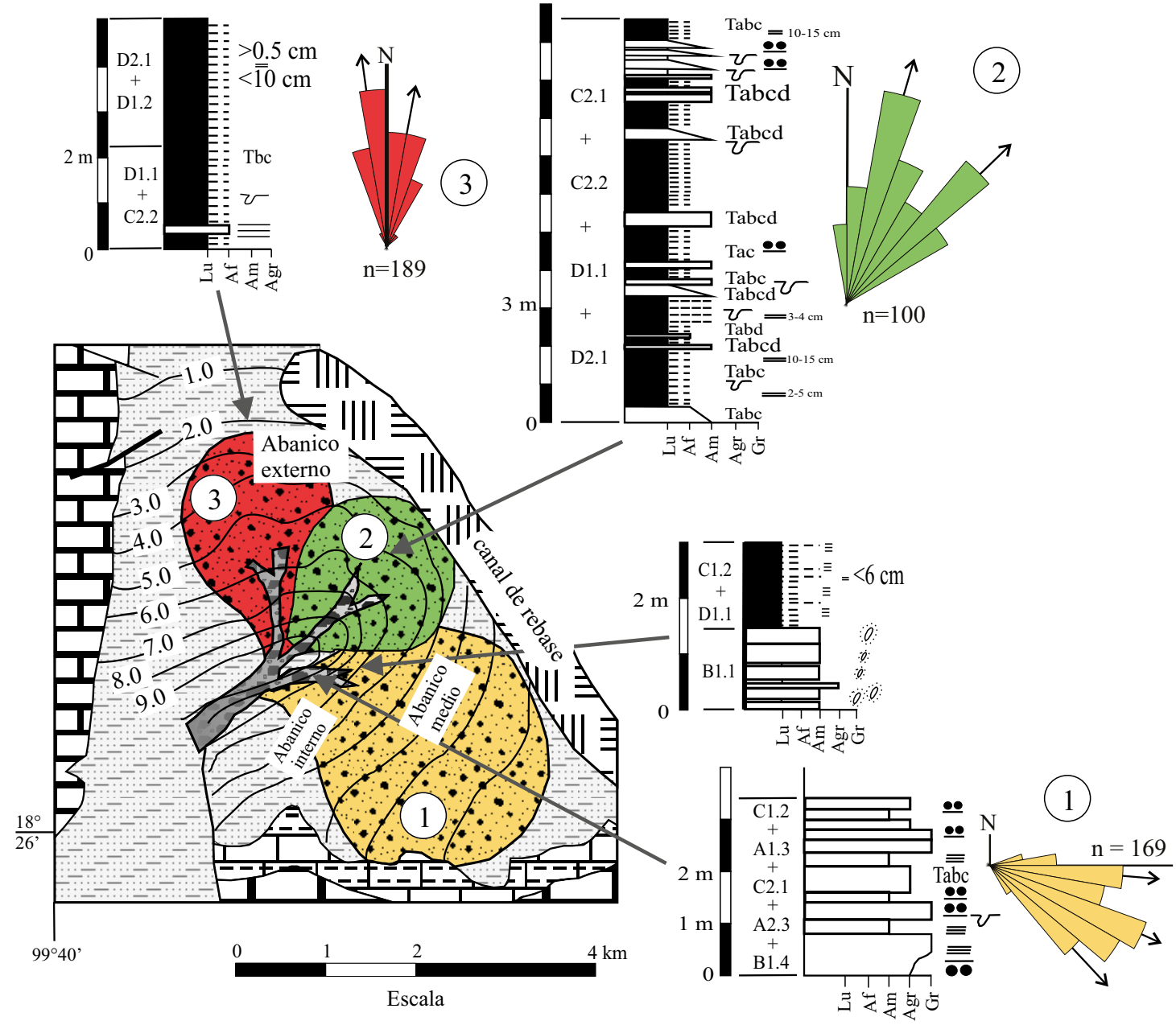

Figura 10. Interpretación sedimentológica del complejo turbidítico de Huixtac-Ojo de Agua, donde se muestran diferentes secciones estratigráficas de cada Sucesión Sedimentaria Profunda y las direcciones de paleocorrientes medidas en surcos de erosión, estructuras de arrastre, saltación de partícula y laminaciones cruzadas de cada uno de los diferentes sistemas turbidíticos documentados en este trabajo. El relleno de los sistemas sedimentarios es sólo representativo; los círculos gruesos en color gris, indican depósitos de las facies de clases A y B; los círculos medianos y pequeños, señalan los depósitos relacionados con las facies de clases B, C y D; las líneas discontinua y puntos, indican abundancia de las facies de clases $\mathrm{C}$ y D. Las sucesiones sedimentarias se señalan con números; p. ej. 1 = Sucesión Sedimentaria 1. La interpretación de los sistemas de depósito y de las líneas de relaciones de lutita/arenisca, corresponde a la distribución geográfica actual.

su parte distante hasta el abanico en su parte media (Figura 10). Las direcciones de los surcos de erosión dentro de los sistemas de canales, determinan rumbos de transporte desde NE20 hasta NE50 (Figura 10). La edad de la sucesión SSP-2 varía del Cenomaniano tardío hasta el Turoniano temprano (Figura 9), como lo determina la asociación faunística de Euomophaloceras, Mantellicreas y Pseudocalycoceras (Fitz-Díaz et al., 2002; Figura 10). La sucesión SSP-3 se caracteriza por abundancia de las facies $\mathrm{C}$ y $\mathrm{D}$, con contenidos menores de $\mathrm{B}$. Las facies $\mathrm{C}$ y D, se presentan como crecimiento frontal progresivo y de acumulación vertical; las primeras se interpretan como sistemas de lóbulo con morfología alargada (AF3 y 5), en tanto, que las sucesiones verticales representan depósitos de desborde de canal, depósitos de intercanal y de canal abandonado (AF4; Figura 10). Las direcciones de los surcos de erosión determinan los rumbos de sedimentación hacia el NW $10^{\circ}$ (Figura 10 ), con dispersión desde NW20 $0^{\circ}$ hasta NE30 $0^{\circ}$. La edad documentada para la sucesión SSP-3 es Turoniano tardío como lo indica la presencia de Barroiciceras sp y Reoveacrinus sp. (RosendoBrito et al., 2002; Figura 9). 


\section{Explicación}

Granulometría
$\mathrm{Lu}=$ Lutita
$\mathrm{Af}=$ Arenisca de grano fino
$\mathrm{Am}=$ Arenisca de grano medio
$\mathrm{Agr}=$ Arenisca de grano grueso
$\mathrm{Amgr}=$ Arenisca de grano muy grueso
$\mathrm{Gn}=$ Gránulos
$\mathrm{Gu}=$ Guijas
$\mathrm{Gj}=$ Guijarros

$\mathrm{Cr}=$ Cantos rodados $\mathrm{Sb}=\operatorname{Losa}$

Estructuras Sedimentarias

으 Gradación normal

- Gradación inversa

=10-60 cm Estratificación variable

$\overline{\bar{\ddots}}$ Laminación paralela
Contenido total o

Tbc parcial de la Secuencia Bouma

$\checkmark$ Estructuras de carga

$\tau$ Surcos de erosión

Ciclos de compensación
bien desarrollados

1.0 Relación de areniscas/lutitas

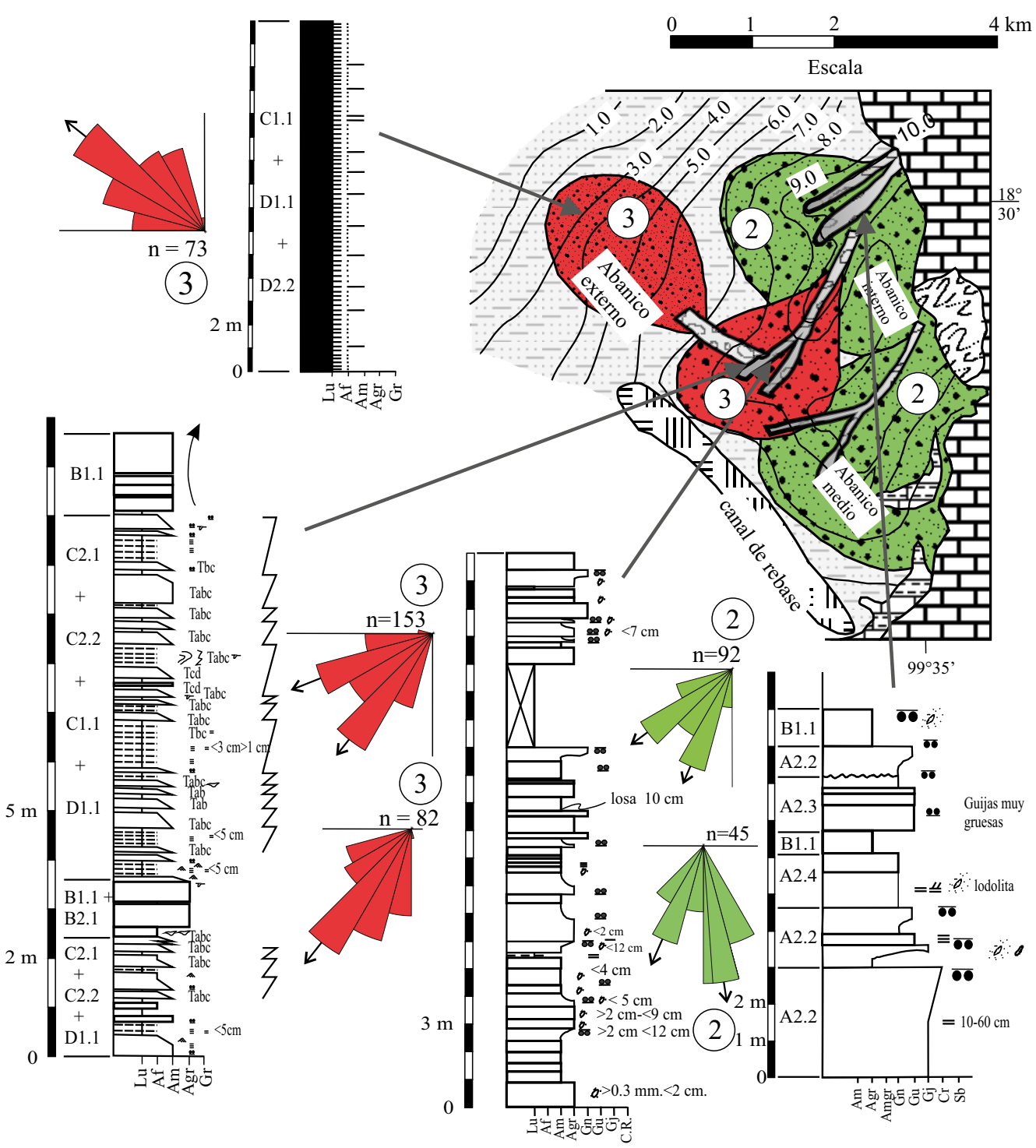

Figura 11. Interpretación sedimentológica del complejo turbidítico de Cerro Gordo-Taxco el Viejo; se muestran las secciones estratigráficas de cada sucesión sedimentaria profunda y las direcciones de paleocorrientes en surcos de erosión, estructuras de arrastre, saltación de partícula y laminaciones cruzadas de cada uno de los diferentes sistemas turbidíticos de este trabajo. El relleno de los sistemas sedimentarios es sólo representativo; los círculos gruesos en color gris, son los depósitos de las clases de facies A y B; los círculos medianos y pequeños, señalan los depósitos relacionados con las facies de clases B, C y D; las líneas discontinuas y puntos, denotan la abundancia de facies de las clases C y D; 2 = Sucesión Sedimentaria 2 y 3 = Sucesión Sedimentaria 3. La interpretación de los sistemas de depósito y de las líneas de relaciones de lutita/arenisca corresponde a la distribución geográfica actual.

\section{Características del dominio de Cerro Gordo-Taxco el Viejo (Cenomaniano tardío-Turoniano tardío)}

La sucesión SSP-2 dentro del dominio de Cerro Gordo-Taxco el Viejo se caracteriza por una mayor abundancia de la facies $C$ que cambian lateralmente o verticalmente a B y A (Figuras 9 y 11). Las facies $\mathrm{C}$ y D se presentan en forma de crecimiento progresivo frontal y de acumulación vertical. Las primeras representan depósitos de lóbulo dentro del abanico medio, tanto en su parte cercana como en la distante (AF5; Figura 11). En tanto que las sucesiones de crecimiento vertical están relacionadas con depósitos de intercanal (AF2), situados en el abanico interno en su parte distante. Las facies A y B se presentan como acumulaciones verticales, representando depósitos de canales de 
tipo mixto con moderada sinuosidad (AF1) y depósitos de la transición lóbulo-canal (AF3). Estos sedimentos se depositaron dentro del abanico interno en su parte distante y así como en el abanico medio en su parte cercana (Figura 11). Las direcciones de los surcos de erosión dentro de estos sistemas de canales, indican direcciones de transporte de sedimentos desde $\mathrm{SE} 10^{\circ}$ hasta SW $30^{\circ}$. Las direcciones de los surcos de erosión y estructuras de arrastre y saltación de partícula indican direcciones de transporte de sedimentos desde SW $25^{\circ}$ hasta $\mathrm{SW} 65^{\circ}$. La edad de la sucesión SSP-2 varía del Cenomaniano tardío hasta el Turoniano temprano (Figura 9), como lo sugiere la asociación faunística Euomophaloceras, Mantellicreas y Pseudocalycoceras (Fitz-Díaz et al., 2002; Figura 9). La sucesión SSP-3 se caracteriza por una mayor abundancia de las facies C, D y, en menor proporción, B y A. Las facies $\mathrm{C}$ y D se presentan en sucesiones de crecimiento frontal progresivo y de acumulación vertical, interpretadas como depósitos de intercanal (AF2), situados en el abanico interno en su parte lejana, depósitos de lóbulo dentro del abanico medio, tanto en su parte cercana como en la lejana (AF5; Figura 11) y como depósitos de cubierta y desborde de canal (AF2). Las facies B y A se disponen en sucesiones verticales interpretadas como depósitos de canal de tipo mixto con moderada sinuosidad (AF1) y depósitos de la transición lóbulo-canal (AF3), depositados dentro del abanico interno en su parte lejana, y dentro del abanico medio, en su parte cercana (Figura 11). Las direcciones de surcos de erosión y estructuras de arrastre y saltación de partículas medidas en los sistemas de lóbulo, indican direcciones de aporte de sedimentos desde $\mathrm{SW} 40^{\circ}$ hasta $\mathrm{NW} 40^{\circ}$ (Figura 11). Las direcciones medidas en surcos de erosión, dentro de los sistemas de canales, indican direcciones de aporte de sedimento hacia el SW $40^{\circ}$ (Figura 11). La edad documentada para la sucesión SSP-3 es del Turoniano tardío como lo denota la presencia de Barroiciceras sp. y Reoveacrinus sp. (Rosendo-Brito et al., 2002; Figura 9).

\section{Configuración de la cuenca, procesos y modelo de depósito}

El análisis de información paleontológica, la distribución de diferentes facies y los datos de paleocorrientes que caracterizan a los dominios de Huixtac-Ojo de Agua y Cerro Gordo-Taxco el Viejo sugieren que, en su inicio, los sistemas turbidíticos de la Formación Mezcala en la porción norte de la cuenca de Taxco-Atlixtac, fueron depositados dentro de un sistema de antefosa con una topografía semiconfinada.
Esta topografía estuvo relacionada con la evolución de la cuenca de Pachivia (Guerrero-Suastegui, 2004), la que posteriormente se aisló y confinó por un área de no-depósito (by-pass), alargada, con orientación NW-SE. Así mismo, permite establecer la evolución tectónica y sedimentaria de la Formación Mezcala en la cuenca de Taxco-Atlixtac en las siguientes fases:

Fase 1: Desarrollo de abanicos submarinos ricos en lodos-arenas dentro de una antefosa simple (Cenomaniano temprano)

El desarrollo inicial de la cuenca de Taxco-Atlixtac está estrechamente relacionado con el origen de la cuenca de Pachivia, la cual se encuentra al occidente, fuera del área de estudio. Ambas cuencas se caracterizan por el desarrollo de sistemas turbidíticos de alta eficiencia (Mutti y Normark, 1987), conformados por sistemas de canal-depósitos de desborde y lóbulo con características de abanicos submarinos ricos en lodos y arenas, tal como se encontró en la sucesión SSP-1 (Reading y Richards, 1994). Esta sucesión está conformada por las facies C y D (AF5 y AF6) y, en menores cantidades, por la facies B. Los depósitos de desborde y los sistemas de intercanal están poco desarrollados, quizá por la moderada sinuosidad que presentan los sistemas de canales, que favorece la erosión de estos sistemas. Los sistemas de lóbulos presentan una morfología radial, como lo marcan las direcciones de paleocorrientes, que indican un transporte preferencial de sedimentos finos hacia el $\mathrm{SE} 65^{\circ}$, con dispersión de sedimentos desde SE40 hasta SE85 (Figura 12). Los sistemas de lóbulo sobreyacen por una discordancia erosiva a la asociación AF8, documentada en la cima de la sucesión terrígena-carbonatada de la Formación Agua Nueva (Guerrero-Suastegui, 2004; Ocampo-Díaz, 2004; Ocampo-Díaz, 2012). Las relaciones estratigráficas y las características sedimentológicas de la asociación AF8 permiten interpretar la edad del inicio de la acreción suave del subterreno Teloloapan contra el Terreno Mixteca. La edad de Cenomaniano temprano de la sucesión SSP-1, denota que estas sucesiones son más jóvenes que las edades del Albiano tardío documentadas en el área de Teloloapan por Guerrero y Ramírez (1992), Guerrero et al. (1993) y Guerrero-Suastegui (2004) con base en un ensamble faunístico de amonites, calciesferúlidos y foraminíferos planctónicos (Figura 1). Estas variaciones en las edades de ambas unidades son concordantes con las edades de deformación documentadas en sucesiones del Terreno Guerrero por Fitz-Díaz et al. (2008). Estos autores sugieren

Tabla 2. Abundancia de las Clases de facies, de estructuras sedimentarias y características sedimentológicas de los dominios de sedimentación documentados en la Formación Mexcala en la región norte de la cuenca de Taxco-Atlixtac.

\begin{tabular}{|c|c|c|c|c|}
\hline \multirow[b]{2}{*}{ Presencia en \% } & \multicolumn{2}{|c|}{ Dominio de Huixtac } & \multicolumn{2}{|c|}{ Dominio de Taxco el Viejo } \\
\hline & $0 \%$ & $100 \%$ & $0 \%$ & $100 \%$ \\
\hline \multicolumn{5}{|l|}{ Clase de facies A } \\
\hline \multicolumn{5}{|l|}{ Clase de facies B } \\
\hline \multicolumn{5}{|l|}{ Clase de facies $\mathrm{C}$} \\
\hline \multicolumn{5}{|l|}{ Clase de facies D } \\
\hline \multicolumn{5}{|l|}{ Desarrollo de canales } \\
\hline \multicolumn{5}{|c|}{ Desarrollo de la transición lóbulo-canal } \\
\hline \multicolumn{5}{|c|}{ Sucesiones altamente arenosas } \\
\hline \multicolumn{5}{|c|}{ Presencia de la Secuencia Bouma } \\
\hline \multicolumn{5}{|c|}{ Relación de lutita-arenisca } \\
\hline \multicolumn{5}{|l|}{ Desarrollo de lóbulos } \\
\hline \multicolumn{5}{|l|}{ Traslape de lóbulos } \\
\hline \multicolumn{5}{|l|}{ Desarrollo de ciclicidad } \\
\hline Espesor Total & & & & \\
\hline
\end{tabular}


que el proceso de acreción del subterreno Teloloapan con la región del México continental ocurrió entre el Albiano y el Cenomaniano temprano (Guerrero-Suastegui, 2004; Guerrero-Suastegui et al., 2006b), lo cual favoreció la ocurrencia de eventos episódicos de alta energía en las cuencas de Pachivia y Taxco-Atlixtac (Einsele, 1996; Einsele et al., 1996; Figura 12). El proceso de colisión posiblemente fue de tipo suave ("soft-collision"; Pickering et al., 1988) entre el subterreno Teloloapan y el Terreno Mixteca, relacionado con una subducción de la placa de Norteamérica hacia el oeste, como lo ha propuesto Ramírez-Espinoza et al. (1991), Guerrero-Suastegui (2004), Ocampo-Díaz et al. (2016). El proceso de colisión suave favoreció el desarrollo de depozonas en antefosa de tipo simple (Ricci-Lucchi, 1986), la migración del sistema de antepaís relacionado con el cinturón orogénico y la propagación de las cuñas orogénicas hacia el este. El desarrollo y propagación de las cuñas orogénicas, y por consecuencia, el desarrollo del cinturón plegado y cabalgado, debieron ser bajos o moderados, con desarrollo de cadenas montañosas de alturas moderadas, en las cuales la exposición y alteración de las áreas fuente debieron haber sido bajas. Esto está indicado por los valores bajos a moderados del Índice de Alteración Química (Guerrero-Suastegui, 2004) en las sucesiones turbidíticas del área de Pachivia, y la presencia de circones detríticos con edades mayores a 1 Ga (Talavera-Mendoza et al., 2007; Figura 11). El incipiente desarrollo del cinturón orogénico favoreció la generación de sistemas turbidíticos de alta eficiencia y sistemas de abanicos ricos en lodos y arenas (Reading y Richards, 1994), depositados en las cuencas de Pachivia y parcialmente en la cuenca de Taxco-Atlixtac. La morfología semi- radial que presentan los sistemas de lóbulos en la cuenca de Pachivia (Guerrero-Suastegui, 2004), indican que la morfología de la cuenca era semi-confinada por altos estructurales, lo cual está relacionado con una corteza que se hundía con poco grado de atenuación (Jordan, 1995; Covault y Romans, 2009). Este marco tectónico favoreció el mejor desarrollo de sistemas de lóbulos semi-radiales y canales con baja a moderada sinuosidad y depósitos de desborde, debido al poco grado de confinamiento de la cuenca (Pickering y Hiscott, 2016; Figura 12). Sin embargo, las direcciones de paleocorrientes medidas en el área de Huixtac-San Juan Unión, indican una dirección perpendicular al frente del cinturón orogénico. Esto permite interpretar que el posible límite entre las cuencas de Pachivia y de Taxco-Atlixtac estuvo relacionado con el desarrollo de altos estructurales, posiblemente anticlinales poco desarrollados con orientación NW-SE. Es probable que hayan existido pequeñas áreas no confinadas por donde migraron los sistemas de canal-depósitos de desborde y lóbulo que conforman la base de las sucesiones clásticas del dominio de Huixtac-Ojo de Agua en la cuenca de Taxco-Atlixtac (Figuras 10 y 12).

Fase 2: Desarrollo de abanicos mixtos en arenas-lodos dentro de un complejo de antefosa (Cenomaniano tardío-Turoniano temprano)

La segunda fase representa el tiempo de máximo depósito de sucesiones arenosas documentadas en la sucesión SSP-2 de ambos dominios dentro de la cuenca de Taxco-Atlixtac, y por consiguiente el período de mayor relleno, subsidencia y desarrollo de esta cuenca (Figuras 9 y 13). Esta fase se caracteriza por el desarrollo de sistemas

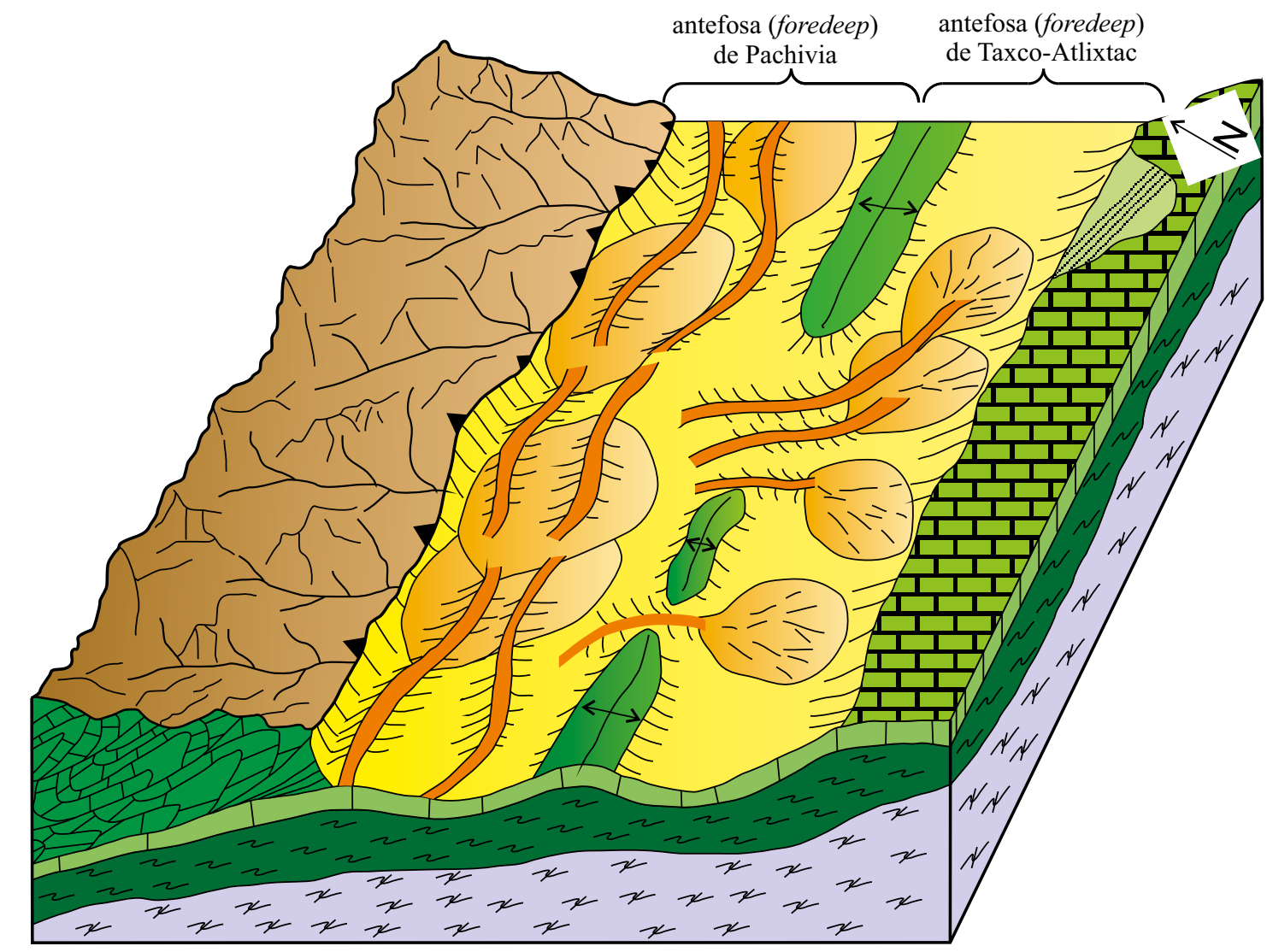

Figura 12. Modelo sedimentológico de la evolución tectónica-sedimentaria de la cuenca de Pachivia y su relación con la cuenca de Taxco-Atlixtac durante el Cenomaniano temprano-Turoniano temprano. El color violeta con símbolos de "s" sesgada y cortada por una línea, denota a las rocas cristalinas previas a las rocas de las formaciones Chapolapa y de la Roca Verde Taxco el Viejo. El color verde oscuro con símbolo "s" sesgada identifica a las unidades de las formaciones Chapolapa y de la Roca Verde Taxco el Viejo. El color verde claro con símbolo de tabique señala a la Formación Morelos. Los depósitos de la cuenca de Pachivia solamente son representativos, dado que no forman parte del presente trabajo y su interpretación se establece con base en el trabajo de Guerrero-Suastegui (2001). 
de canal-depósitos de desborde, transición lóbulo-canal y lóbulos con características similares a los abanicos mixtos en arenas-lodos (Reading y Richards, 1994), representando sistemas de baja eficiencia, de acuerdo con el esquema de Mutti y Normark (1987). Los sistemas de canales desarrollados en esta fase de sedimentación, en ambos dominios, son del tipo erosivo y mixto (AF3; Mutti y Normark, 1987). Su morfología fue de moderada sinuosidad con mejor desarrollo de depósitos de intercanal (AF2) y de sistemas de sedimentos de desborde (AF2), que se depositaron en la región del abanico submarino medio en su parte cercana y lejana dentro del modelo de Mutti y Ricci-Lucchi (1972). Los sistemas de lóbulo (AF5) en ambos dominios están mejor desarrollados que durante la fase de sedimentación 1. Estos lóbulos se caracterizan por la presencia completa o parcial de la secuencia Bouma, y diversos ciclos de compensación (Mutti y Normark, 1987) que denotan sus procesos de apilamiento vertical y crecimiento lateral. Los depósitos de lóbulo sobreyacen de manera concordante a la asociación AF7. Los sistemas de canales del complejo turbidítico de Huixtac-Ojo de Agua tuvieron una moderada sinuosidad, con direcciones preferenciales hacia el NE $20^{\circ}-\mathrm{NE} 50^{\circ}$, indicando un transporte de sedimentos siguiendo el eje del cinturón orogénico (Figura 13). Por otro lado, los sistemas de canales del complejo Cerro Gordo-Taxco el Viejo presentan direcciones preferenciales hacia el SW $40^{\circ}$, denotando un transporte opuesto al eje del cinturón orogénico, posiblemente derivado de una región elevada, muy similar a la región de la inflexión tectónica positiva (forebulge o alto estructural) (Figura 13). El desarrollo de sistemas de la transición lóbulo-canal durante esta fase de sedimentación, en ambos dominios, es mayor que durante la fase de sedimentación 1. Esto implica que la morfología de la cuenca fue más atenuada, lo que favoreció el desarrollo de cambios en la pendiente, como puede ser la instauración de la inflexión tectónica positiva, en donde es más favorable desarrollar el depósito de estos sistemas (Mutti y Normark, 1987). El complejo turbidítico de Cerro Gordo-Taxco el Viejo presenta el mayor desarrollo de los depósitos de la transición lóbulo-canal. Esto permite interpretar la evolución de la región por inflexión tectónica, la cual favoreció morfologías abruptas en ambos márgenes de la cuenca de Taxco-Atlixtac, con desarrollo de áreas de mayor pendiente, en donde es común el desarrollo y depósito de estos sistemas (Wynn et al., 2002b). Las direcciones de paleocorriente, relacionadas con surcos de erosión de los sistemas de lóbulos del dominio de Huixtac-Ojo de Agua, indican direcciones preferenciales hacia el NE2 $0^{\circ}$, mientras que los vectores de flujo de las direcciones de estructuras relacionadas con saltación y arrastre de partículas varían desde $\mathrm{NW} 10^{\circ}$ hasta $\mathrm{NE} 60^{\circ}$ (Figura 13). Estas variaciones en los vectores de paleocorrientes (surcos de erosión vs. estructuras de arrastre y saltación de partículas) permiten interpretar que los lóbulos del dominio de Huixtac-Ojo de Agua se desarrollaron con morfología alargada. Los lóbulos inicialmente se depositaron con rumbo $\mathrm{NE} 60^{\circ}$ y fueron migrando y traslapándose con rumbo $\mathrm{NW} 10^{\circ}$, como lo denota la presencia de diversos ciclos de compensación (Figura 10). Por otro lado, las direcciones de flujo medidas en surcos de erosión en los sistemas de lóbulo del dominio de Cerro Gordo-Taxco el Viejo, indican rumbos preferenciales hacia el $\mathrm{SW} 40^{\circ}$. Por otro lado, los rumbos de dispersión de sedimentos varían desde $\mathrm{SW} 30^{\circ}$ hasta $\mathrm{NW} 40^{\circ}$, los cuales

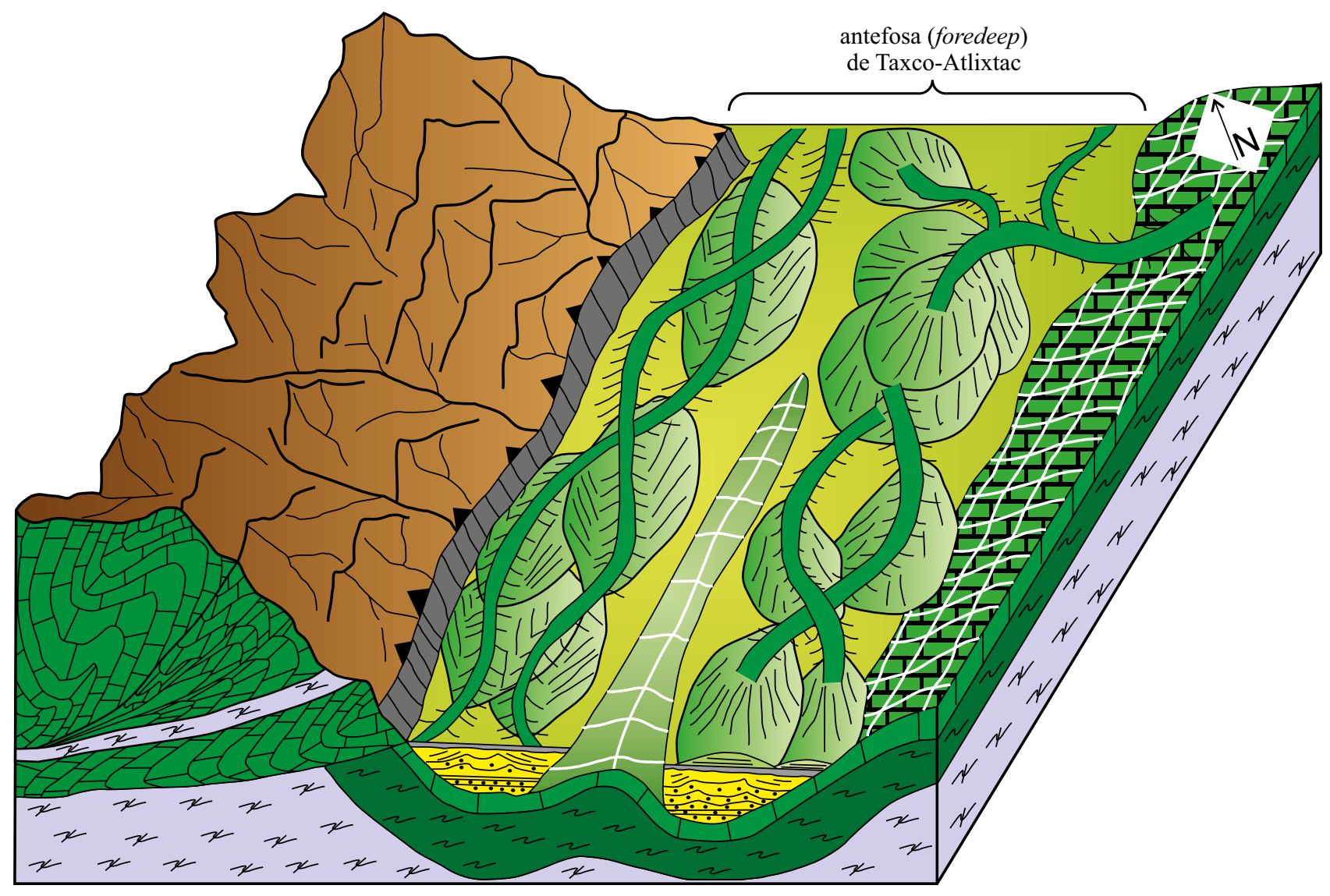

Figura 13. Modelo sedimentológico de la evolución tectónica-sedimentaria de la cuenca de Taxco-Atlixtac durante el Cenomaniano tardío-Turoniano temprano, fase de sedimentación 2 . El color violeta con símbolos de "s" sesgada y cortada por una línea, denota a las rocas cristalinas previas a las formaciones Chapolapa y de la Roca Verde Taxco el Viejo. El color verde oscuro con símbolo "s" sesgada, hace referencia a las unidades de las formaciones Chapolapa y de la Roca Verde Taxco el Viejo. El color verde claro con símbolo de tabique hace referencia a la Formación Morelos. 
se midieron en estructuras de saltación y arrastre de partículas (Figuras 11 y 13). Esta información permite interpretar que los sistemas de lóbulos de la sucesión SSP-2 del dominio de Cerro-Gordo-Taxco el Viejo desarrollaron una morfología semi-radial (Figura 13). Aunado a esto, los datos de paleocorrientes en el dominio de Cerro Gordo-Taxco el Viejo indican que las direcciones de flujo -en el noroeste del poblado de Tecalpulco-, cambian abruptamente hacia el S y al NW40 . Este cambio en las direcciones de paleocorrientes, permite interpretar que los sistemas de canales submarinos documentados en el dominio de Cerro Gordo-Taxco el Viejo, presentaban una sinuosidad moderada. Este factor favoreció la generación de zonas de rompimiento de las márgenes de los canales, donde se genera el desborde de la sobrecarga de sedimentos que son transportados por corrientes turbidíticas de alta y baja densidad. De esta forma ocurrió el depósito de sucesiones de lóbulo y abanico externo en las regiones de Santiago Temixco y Atzala (Figura 13). Estas variaciones en los vectores de paleocorrientes robustecen la interpretación de que la corteza de la cuenca de TaxcoAtlixtac, durante esta fase de sedimentación, presentó un mayor grado de atenuación. Esto pudo propiciar la generación de anticlinales que confinaron y favorecieron el desarrollo de los sistemas de canales, la migración y traslape de los sistemas de lóbulos en ambos sistemas y el desarrollo de canales de transporte o no-depósito de la sobrecarga de sedimentos en el dominio de Cerro Gordo-Taxco el Viejo (Ricci-Lucchi, 1986; Kneller et al., 1991; Lomas y Joseph, 2004; Figuras 11 y13). Estos cambios en los patrones de sedimentación y el incremento en el grado de atenuación de la corteza, posiblemente están relacionados con la evolución de una antefosa simple (estadio de sedimentación 1) a una antefosa compleja, como lo ha documentado Ricci-Lucchi (1986) en el sistema de antepaís de los Apeninos. El cambio de estilo de antefosa en la cuenca de Taxco-Atlixtac fue favorecido, muy posiblemente, por un proceso de colisión "dura" (s.s. Pickering et al., 1988) del subTerreno Teloloapan contra el Terreno Mixteca, en este caso, con un sistema de subducción con polaridad hacia el este, como lo ha propuesto Ramírez-Espinoza et al. (1991) y Guerrero-Suastegui (2004). Este evento de colisión dura, favoreció el mayor desarrollo del cinturón plegado y cabalgado, un mayor avance de las cuñas orogénicas, mayor profundidad de exhumación, mayor erosión y una mayor atenuación de la corteza que se hundía, lo que propició la generación de sistemas de abanicos mixtos de arena-lodo y la evolución de un sistema de antefosa simple a antefosa compleja (Reading y Richards, 1994; Ricci-Lucchi, 1986; Figura 12 y 13). El mayor avance de las cuñas orogénicas hacia la región central de México y el incremento en el grado de disección de las rocas de la corteza inferior (i.e., complejo Acatlán), está apoyado por la presencia de circones detríticos con edades mayores a $160 \mathrm{Ma}$ (Talavera-Mendoza et al., 2007). De acuerdo con Lawton et al. (2016), los circones se derivaron del arco Nazas-Chapolapa (170-200 Ma), de la orogenia Apalachiana (300-500 Ma), de la orogenia Pan-Africana (550-780 Ma) y de la orogenia Grenvilliana (1.0-1.2 Ga), que han sido

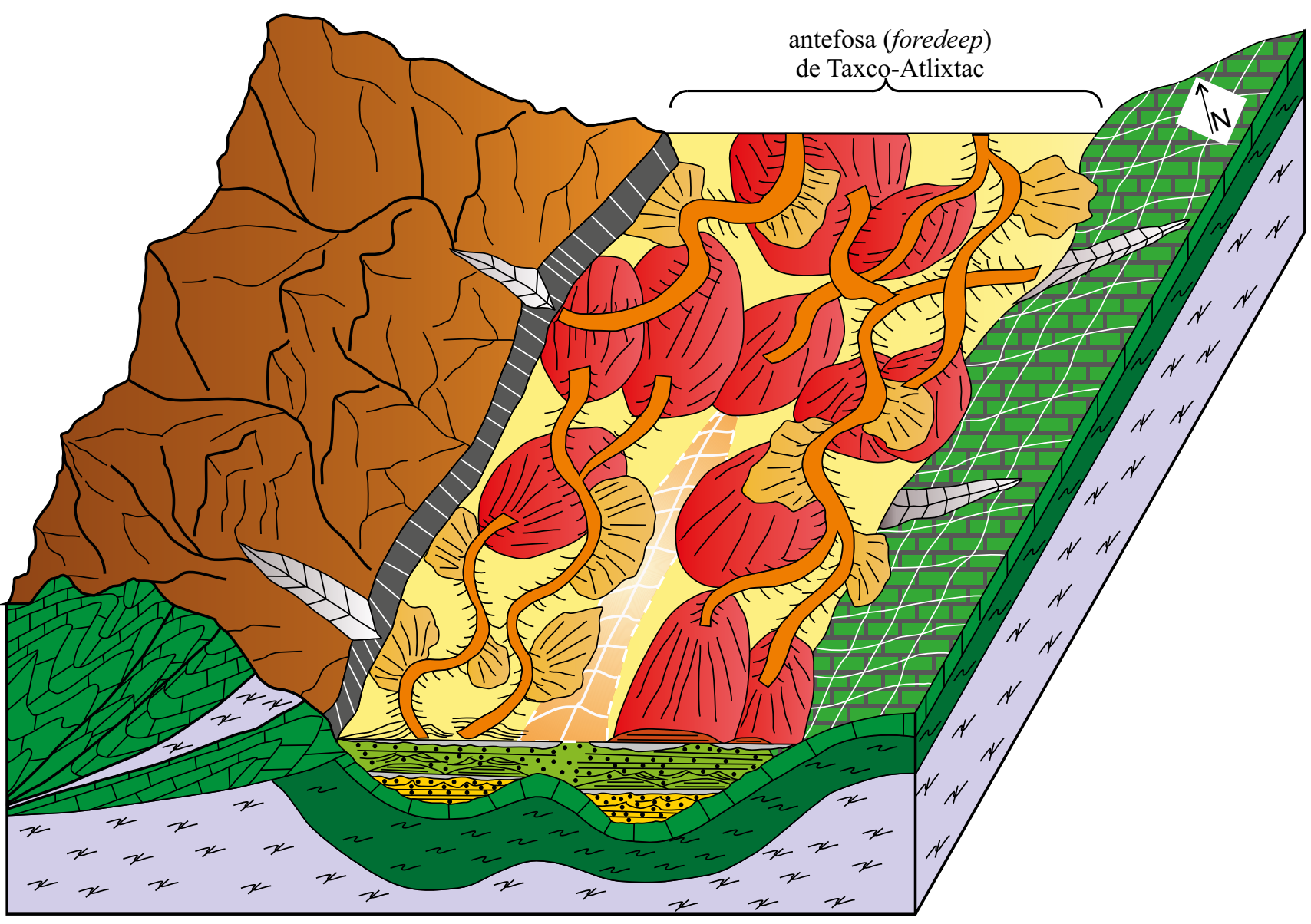

Figura 14. Modelo sedimentológico de la evolución tectónica-sedimentaria de la cuenca de Taxco-Atlixtac durante el Turoniano temprano a tardío, fase de sedimentación 3. El color violeta con símbolos de "s" sesgada y cortada por una línea denota a las rocas cristalinas previas a las formaciones Chapolapa y de la Roca Verde Taxco el Viejo. El color verde oscuro con símbolo "s" sesgada hace referencia a las unidades de las formaciones Chapolapa y de la Roca Verde Taxco el Viejo. El color verde claro con símbolo de tabique hace referencia a la Formación Morelos. 
documentados en diversas regiones de los estados de Guerrero, Puebla y Oaxaca (Talavera-Mendoza et al., 2007; Sierra Rojas et al., 2016). Esta propuesta de aporte de sedimentos antiguos que derivaron de rocas con estas edades y que fueron exhumadas por desarrollo y avance frontal de cuñas orogénicas, es similar a la propuesta de Talavera-Mendoza et al. (2007), quien propone que estos circones fueron reciclados, dado que presentan similitudes en los picos de edades con las rocas del Complejo Acatlán.

Fase 3: Depósitos de suspensión, traslape de los lóbulos y bifurcación de corrientes (Turoniano tardio?-Coniaciano temprano)

Durante la tercera fase de sedimentación se depositó la sucesión SSP-3 dentro de ambos dominios; esta sucesión se caracteriza por secuencias lodo-arenosas que desarrollaron sistemas de canal-depósitos de desborde y lóbulo, con características similares a los sistemas de abanicos ricos en lodos y arenas (Reading y Richards, 1994). Estos depósitos se distinguen por amplias sucesiones rítmicas de lutita y arenisca que constituyen las facies $\mathrm{C}$ y D; se interpretan como depósitos de lóbulos dentro del abanico externo en su parte cercana, y que pertenecen a la facies B, que caracteriza a sistemas de canales de depósito (Mutti y Normark, 1987). Los depósitos de lóbulo sobreyacen concordantemente a conglomerados resedimentados de la facies A2.2 (Figura 12), los cuales, se interpreta, marcan el límite de sedimentación entre la fase 2 y fase 3 . Los vectores promedio de las direcciones de paleocorrientes, medidos en los depósitos de lóbulos del dominio de Huixtac-Ojo de Agua, indican que éstos se depositaron de manera alargada con direcciones variables entre $\mathrm{NW} 10^{\circ}$ y NE20 $0^{\circ}$, siguiendo la traza de un desvío de la carga de sedimento fino generado en la Fase 2 (Figura 14). En tanto, los depósitos de lóbulo del dominio del Cerro Gordo-Taxco el Viejo, se depositaron de manera elongada con direcciones preferenciales desde SW $40^{\circ}$ hasta NW40, como lo marcan las direcciones de paleocorrientes y el patrón de las relaciones de lutita-arenisca (Figura 11). Un rasgo importante que se observa en el mapa de distribución de paleocorrientes, en las inmediaciones de los poblados de Santiago Temixco y Tecalpulco, es una dirección oblicua a la dirección preferencial de distribución de sedimentos, muy similar a la orientación de la sedimentación de la fase 2 . Estos patrones indican que el canal de desvío (by pass) al inicio de esta fase de sedimentación, aún estaba activo. Este factor favoreció la bifurcación y la migración de los sistemas de lóbulo hacia la región de Santiago Temixco, y que posteriormente fueron cubiertos por los sistemas de abanicos submarinos ricos en lodo y arena. Las direcciones de paleocorrientes y la distribución de facies indican que después del soterramiento del canal de desvío, ambos sistemas fueron traslapados, rellenando y colmando la cuenca de Taxco-Atlixtac (Figura 14). Este proceso de solapamiento se infiere por el contraste de las direcciones de los vectores promedio de surcos de erosión, en las inmediaciones del poblado de Santiago Temixco (Figuras 10, 11 y 14). Las características de la última fase de sedimentación, y sobre todo la similitud con los sistemas de abanicos ricos en lodos y arenas, sugieren que el desarrollo del cinturón plegado y cabalgado y de las cuñas orogénicas, durante esta etapa de sedimentación, fue lento o casi nulo. Este proceso posiblemente ocurrió por medio de una colisión suave (s.s. Pickering et al., 1988), lo cual favoreció condiciones de aporte de sedimentos de grano fino, transportados principalmente por corrientes turbidíticas de baja densidad y por algunas de alta densidad.

\section{CONCLUSIONES}

El presente estudio sedimentológico permite concluir que la Formación Mezcala, en la región norte de la cuenca de Taxco-Atlixtac muestra:
Cuatro clases de facies y 22 facies características de abanicos submarinos, todas ellas relacionadas con el transporte de sedimentos por corrientes turbidíticas de alta y baja densidad, flujos de escombro arenosos, flujos de granos y flujos de cubierta, y una facies relacionada con depósitos de tormenta y alto oleaje, o bien, con eventos de alta energía.

Ocho asociaciones de facies relacionadas con diferentes subambientes de sistemas de abanico submarino, ricos en lodos-arenas y arenas-lodos. Los sub-ambientes varían de canales de tipo erosivo, mixto y de depósito, transición lóbulo-canal, sistemas de intercanal, sistemas de depósitos de desbordamiento a lóbulos y abanico externo en una zona de planicie de cuenca; esta sedimentación tuvo lugar en la región del abanico interno en su parte distante y dentro del abanico externo en su parte media.

La cartografía de facies, los mapas de relación de lutitas-areniscas, el análisis de los vectores de paleocorrientes y el análisis de datos paleontológicos, permitieron determinar la presencia tres Sucesiones de Sedimentación Profunda (SSP-1, 2 y 3) distribuidas dentro de dos dominios de sedimentación denominados Huixtac-Ojo de Agua (SSP-1, 2 y 3) y Cerro Gordo-Taxco el Viejo (SSP-2 y 3). El dominio de Huixtac-Ojo de Agua muestra un predominio de facies de las clases lodo-arenosa y areno-lodosas, con abundancias menores de clases de facies conglomerádicas y arenosas. Los sub-ambientes que los constituyen son canales erosivos, mixtos y de depósito, sedimentos de la transición lóbulo canal, poco desarrollada y/o conservada, lóbulo, depósitos de desbordamiento y depósitos de intercanal. El dominio de Cerro Gordo-Taxco el Viejo presenta una mayor abundancia facies de las clases arenosas y conglomerádicas, con proporciones menores de clases areno-lodosas y lodosas. Los sub-ambientes que caracterizan a este dominio son canales erosivos, de depósito y mixtos, depósitos de la transición lóbulo-canal, depósitos de intercanal, depósitos de lóbulo, depósitos de cubierta, desborde de canal y depósitos de abanico externo.

Las direcciones promedio de paleocorrientes en el dominio de Huixtac-Ojo de Agua son SE65 ${ }^{\circ}$, NE2 $0^{\circ}-60^{\circ}$ y NW $10^{\circ}$, mientras que en el dominio de Cerro Gordo-Ojo de Agua los rumbos preferenciales son $\mathrm{SE} 10^{\circ}-\mathrm{SW} 30^{\circ}$, con un cambio hacia el NW $40^{\circ}$. Ambos dominios se depositaron en cuencas de antefosa dentro de un sistema de antepaís. Estos patrones de paleocorrientes denotan direcciones de transporte paralelas al eje del cinturón orogénico y derivados de una región elevada muy similar a la región de la inflexión tectónica (forebulge).

Los resultados del análisis sedimentológico y de los datos paleontológicos permiten establecer que la evolución de la cuenca de Taxco-Atlixtac se efectuó en tres fases de sedimentación: 1) en la fase 1, se depositó la SSP-1 conformada por facies de las clases C y D, relacionadas con el desarrollo de abanicos submarino ricos en lodosarenas dentro del dominio de Huixtac-Ojo de Agua. Estos abanicos se formaron dentro de un sistema de antefosa simple, relacionado con el desarrollo de fallas inversas y cabalgaduras con poca exposición, producto de una colisión de tipo suave entre el subterreno Teloloapan y el Terreno Mixteca; 2) durante la fase 2 se depositó la sucesión SSP-2, conformada mayormente por facies de las clases $\mathrm{B}$ y A, dentro de una antefosa compleja. Se interpreta que hubo una mayor exhumación y erosión de los frentes de cabalgaduras que fueron producto de un proceso de colisión "dura" entre el subterreno Teloloapan contra el Terreno Mixteca; y 3) durante la fase 3 se depositó la sucesión SSR-3 en ambos dominios, con un predominio de facies de las clases $\mathrm{C}$ y $\mathrm{D}$, con características de depósito similares a los sistemas de abanicos submarinos ricos en lodos-arenas y del sedimento en suspensión que fueron favorecidos por el poco desarrollo del cinturón orogénico y de las cuñas orogénicas. Se infiere la clausura de la cuenca de Taxco-Atlixtac muy posiblemente por medio de un proceso de colisión "suave". 


\section{AGRADECIMIENTOS}

El primer autor agradece a Benjamín Rosendo-Brito, Vladimir Nicolás Ocampo-Díaz y Martín Filguera-Flores, por su apoyo durante las jornadas de campo. A Sonia Torres por lo comentarios realizados a la versión temprano del manuscrito. El segundo autor agradece de manera especial a todos los estudiantes, que, a partir de los trabajos de tesis, han ayudado a entender la sedimentación y tipo de cuenca de la secuencia de Cretácico Superior del estado de Guerrero, y su importancia en la tectónica de la región. A los árbitros, las doctoras Claudia Mendoza Rosales y Elena Centeno García y al Dr. José Rafael Barboza Gudiño, quienes con sus comentarios han enriquecido este manuscrito. A los editores en jefe de la Revista Mexicana de Ciencias Geológicas, los Drs. Peter Schaaf y Ángel Nieto, por sus valiosas contribuciones que han enriquecido el presente trabajo.

\section{REFERENCIAS}

Aguilera-Franco, N., 1995, Litofacies, paleoecología y dinámica sedimentaria del Cenomaniano-Turoniano en el área de Zotoltitlán-La Esperanza, estado de Guerrero, México: Distrito Federal, México, Universidad Nacional Autónoma de México, tesis de maestría, 137 pp.

Aguilera-Franco, N., 2000, High resolution stratigraphy and paleoecology of the Cenomanian-Turonian succesion, southern Mexico: London, United Kingdom, University of London, tesis doctoral, $202 \mathrm{pp}$.

Aguilera-Franco, N., Hernández-Romano, U., 2004, Cenomanian-Turonian facies succession in the Guerrero-Morelos basin, southern Mexico: Sedimentary Geology, 170, 135-162.

Aguilera-Franco, N., Hernández-Romano, U., Barceló-Duarte, J., MartínezMedrano, M., 1998, Cambios litológicos y paleontológicos registrados a través del límite Cenomaniano-Turoniano en la región de Zotoltitlán-La Esperanza, Guerrero: Implicaciones sedimentológicas: Revista de la Sociedad Mexicana de Paleontología, 8(2), 107-122.

Aguilera-Franco, N., Hernández-Romano, U., Allison, P.A., 2001, Biostratigraphy and environmental change across the Cenomanian/Turonian boundary, southern Mexico: Journal of South American Earth Sciences, 14, 237-255.

Alencáster, G., 1980, Moluscos del Maastrichtiano de Texmalac, Guerrero, en Libreto-Guía de la Excursión Geológica a la Parte Central del Alto Río Balsas (Estados de Guerrero y Puebla), V Convención Geológica Nacional: México, D.F., Sociedad Geológica Mexicana, 39-42.

Bouma, H.A., 1962, Sedimentology of some flysch deposits: Amsterdam/New York, Elsevier Publishing Company, 58 pp.

Brenchely, P.J., 1985, Storm influenced sanstone beds: Modern Geology, 9, 369-396.

Campa, U., M.F., 1975, Las rocas Ígneas y Metamórficas del área de TaxcoTeloloapan, Guerrero, México: Distrito Federal, México, Universidad Nacional Autónoma de México, tesis de maestría, 95 pp.

Campa, M.F., Coney, P.J., 1983, Tectono-stratigraphic terranes and mineral resource distributions of Mexico: Canadian Journal of Earth Sciences, 20, 1040-1051.

Campa-Uranga, M.F., Iriondo, A., 2004, Significado de dataciones cretácicas de los arcos volcánicos de Taxco, Taxco Viejo y Chapolapa, en la evolución de la plataforma Guerrero-Morelos, en IV Reunión Nacional de Ciencias de la Tierra: Juriquilla, Querétaro, Sociedad Geológica Mexicana, 76.

Campa, U.M.F., Ramírez, E.J., 1979, La evolución geológica y la metalogénesis de Guerrero: Chilpancingo, Guerrero, Universidad Autónoma de Guerrero, Serie Técnico-Científica, 1, 84 pp.

Campa, U.M.F., Campos, M., Flores, R., Oviedo, R., 1974, La sequencia mesozoica volcánico-sedimentaria metamorfizada de Ixtapan de la Sal, Mex.-Teloloapan, Gro.: Boletín de la Sociedad Geológica Mexicana, 35, 7-28.

Campa, U.M.F., Ramírez, E.J., Bloome, C., 1982, La secuencia volcánicosedimentaria metamorfizada del Triásico (Ladiano-Cárnico) de la región de Tumbiscatío, Michoacán, en VI Convención Geológica Nacional: México, Distrito Federal, Sociedad Geológica Mexicana, 48.

Campa-Uranga, M.F., Torres de León, R., Iriondo, A., Premo, W.R., 2012
Caracterización geológica de los ensambles metamórficos de Taxco y Taxco el Viejo, Guerrero, México: Boletín de la Sociedad Geológica Mexicana, 64(3), 369-385

Centeno-Garcia, E., Corona-Chávez, P., Talavera Mendoza, O., Iriondo, A., 2003, Geology and tectonic evolution of the western Guerrero terrane-a transect from Puerto Vallarta to Zihuatanejo, Mexico, in Geological transects across Cordilleran Mexico, Guidebook for the field trips of the 99th Geological Society of America Cordilleran Section: Distrito Federal, México, Instituto de Geología, Universidad Nacional Autónoma de México, 201-228.

Centeno-García, E., Guerrero-Suastegui, M., Talavera-Mendoza, O., 2008, The Guerrero composite terrane of western Mexico; collision and subsequent rifting in a supra-subduction zone en Draut, A., Clift, P.D., Scholl, D.W., (eds), Formation and Application of Sedimentary Record in Arc Collision Zones: Boulder, Colorado, Geological Society of America Special Paper 436, 279-308.

Centeno-García, E., Busby, C., Busby, M., Gehrels, G., 2011, Evolution of the Guerrero composite terrane along the Mexican margin, from extensional fringing arc to contractional continental arc: Geological Society of America Bulletin, 123(9-10), 1776-1797.

Covault, J.A., Romans, B.W., 2009, Growth patterns of deep-sea fans revisited: Turbidite-system morphology in confined basins, example from California borderland: Marine Geology, 265, 51-66.

Dávila, V.M., Guerrero, S.M., 1990, Una edad basada en radiolarios para la secuencia volcánica-sedimentaria de Arcelia, estado de Guerrero, en $10^{\text {a }}$ Convención Geológica Nacional: Distrito Federal, México, Sociedad Geológica Mexicana, 83.

De Cserna, Z., 1978, Notas sobre la geología de la región comprendida entre Iguala, Cd. Altamirano y Temascaltepec, edos. de Guerrero y México: Distrito Federal, México, Sociedad Geológíca Mexicana, 1-25.

Delgado-Argote, L., López-Martínez, M., York, D., Hall, C.M., 1990, Geology and geochronology of ultramafic localities in the Cuicateco and Tierra Caliente complexes, southern Mexico, in Geological Society of America, Abstracts with Programs, 22(7), 326.

Díaz-Fernández, J., Ocampo-Díaz, Y.Z.E., Guerrero-Suastegui, M., RamírezEspinosa, J., 2006, Evidencias de depósitos mareales y tormenta en la Formación Mezcala (Cretácico Superior) en la región de AhuexotitlanTlamixtlahuacan, Gro., en V Reunión Nacional de Ciencas de la Tierra, Puebla, Puebla, México, Sociedad Geológica Mexicana, 13.

Dott, J.H.R., Bourgeois, J., 1982, Hummocky stratification: Significance of its variable bedding sequences: Geological Society of America Bulletin, 33, 663-680.

Einsele, G., 1996, Event deposits: The role of sediment supply and relative sealevel changes-overview: Sedimentary Geology, 104, 11-37.

Einsele, G., Chough, S.K., Shiki, T., 1996, Depositional events and their recordsan introduction: Sedimentary Geology, 104, 1-9.

Estrada-Flores, R., 1995, Análisis, distribución e interpretación de las facies turbiditicas de una porción de la Formación Mezcala: Taxco el Viejo, Guerrero, Universidad Autónoma de Guerrero, tesis de licenciatura, 52 pp.

Filguera-Flores, M., 2010, Evaluación del uso de estructuras de paleocorrientes en secuencias deformadas: Formación Mezcala, Cretácico Superior, norte del estado de Guerrero: Taxco el Viejo Guerrero, Universidad Autónoma de Guerrero, tesis de licenciatura, $90 \mathrm{pp}$.

Fitz-Díaz, E., Bravo., C., Ocampo-Díaz, Y.Z.E., Palacios-Castro, E., García-Ortiz, M., Rosendo-Brito, B., Buitrón, B.E., Guerrero-Suastegui, M., 2002, Nuevas localidades fosiliferas dentro de la Formación Mezcala al norte del estado de Guerrero, en VII Congreso Nacional de Paleontología: Guadalajara, Jalisco, México, Sociedad Mexicana de Paleontología, 50.

Fitz-Díaz, E., Tolson, G., Camprubi, A., Rubio-Ramos, M.A., Prol-Ledesma, R.M., 2008, Deformación, vetas, inclusiones fluidas y la evolución tectónica de las rocas cretácicas de Valle de Bravo, estado de México, México: Revista Mexicana de Ciencias Geológicas, 25(1), 59-81.

Fries, C., 1960, Geología del Estado de Morelos y de partes adyacentes de México y Guerrero, región central y meridional de México: Boletín del Instituto de Geología, Univesidad Nacional Autónoma de México, 60, 236 pp.

Galloway, W.E., Hobday, D.K., 1996, Terrigenous clastic depositional system: Berlin, Springer-Verlag, 186-213.

García-Díaz, J.L., 2004, Etude géologique de la Sierra Madre del Sur aux environs de Chilpancingo et d'Olinalá, Gro.: Une contribution à la connaissance de l'évolution géodynamique de la marge pacifique du Mexique depuis le 
Jurassique: Chambery, France, University de Savoie, tesis doctoral, 148 pp.

González-Pacheco, V.V., 1988, Estratigrafía y condiciones paleoambientales de la secuencias cretácicas del área de Atenango del Río, Edo. de Guerrero: Distrito Federal, México, Universidad Nacional Autónoma de México, tesis de licenciatura, $102 \mathrm{pp}$.

González-Pacheco, V.V., 1991, Evolución sedimentológica y diagénesis del Cretácico de la porción norte del estado de Guerrero: Distrito Federal, México, Universidad Nacional Autónoma de México, tesis de maestría, $180 \mathrm{pp}$.

Grajales, M., López, M., 1984, Estudio petrogenético de las rocas ígneas y metamórficas en el Prospecto Tomatlán-Guerreo-Jalisco: Instituto Mexicano del Petróleo, Subdirección de Tecnología y Exploración, Proyecto C-1160 (no publicado).

Guerrero-Suastegui, M., 2004, Depositional and tectonic history of the Guerrero terrane, Sierra Madre del Sur, with emphasis on sedimentary successions of the Teloloapan area, southwestern Mexico: Newfounland, Canada, Memorial University, tesis doctoral, $332 \mathrm{pp}$.

Guerrero-Suastegui., M., Ramírez-Espinosa, J., 1992, Depósitos de tormenta en el límite de la sedimentación de carbonatos y terrígenos (Cretácico Medio) en la región norte del estado de Guerrero, en XI Convención Geológica Nacional: Sociedad Geológica Mexicana, 100-103.

Guerrero-Suastegui, M., Ramírez-Espinosa, J., Talavera-Mendoza, O., CampaUranga, M.F., 1991, El desarrollo carbonatado del Cretácico Inferior asociado al arco de Teloloapan, noroccidente del estado de Guerrero, en Convención sobre la Evolución Geológica Mexicana, ler. Congreso Mexicano de Mineralogía: Pachuca, Hidalgo, Sociedad Mexicana de Mineralogía, 67.

Guerrero-Suastegui, M., Ramírez-Espinosa.J., Gómez- Luna, M.E., GonzálezPacheco, V., Martínez, C.A., 1993, Depósitos de tormenta y fauna fósil asociada del Albiano Superior "Formación Teloloapan" Noreste del Estado de Guerrero, en IV Congreso Nacional de Paleontología: Sociedad Mexicana de Paleontología, 93-97.

Guerrero-Suastegui, M., Ramírez-Espinosa, J., Ocampo-Díaz, Y.Z.E., 2006a, Petrografía y procedencia de areniscas de la Formación Mezcala, Cretácico Superior del estado de Guerrero, en V Reunión Nacional de Ciencias de la Tierra: Puebla, Puebla, México: Sociedad Geológica Mexicana, 15.

Guerrero-Suastegui, M., Ramírez-Espinosa, J., Ocampo-Díaz, Y.Z.E., GaribayRomero, L.M., Gómez-Luna, M.E., Hurtado-Brito, J.C., 2006b, Análisis paleontológico y su importancia en la evolución geológica del Cretácico Superior (Formación Mezcala) del estado de Guerrero, en V Reunión Nacional de Ciencias de la Tierra: Puebla, Puebla, México, Sociedad Geológica Mexicana, 43.

Guerrero-Suastegui, M., Ocampo-Díaz, Y.Z.E., Hiscott, R..N., RamírezEspinosa, J., García-Díaz, J.L., 2010, Orogenia Laramide o acreciónamalgamación de terrenos: Evolución estratigráfica-sedimentológica e implicaciones tectónicas de la cubierta cretácica superior (Formación Mezcala), región norte del estado de Guerrero, en Geo-Laramide: Hermosillo, Sonora, México, Estación Regional del Noroeste, Instituto de Geología, Universidad Nacional Autónoma de México, 9.

Hernández-Romano, U., 1999, Facies, stratigraphy, and diagenesis of the Cenomanian-Turonian of the Guerrero-Morelos platform, southern Mexico: London, United Kingdom, Univeristy of Reading, tesis doctoral, $322 \mathrm{pp}$.

Hernández-Romano, U., Aguilera-Franco, N., Martínez-Medrano, M., BarcelóDuarte, J., 1997, Guerrero-Morelos Platform drowning at the CenomanianTuronian boundary, Huitziltepec, area, Guerrero state, southern Mexico: Cretaceous Research, 18, 661-686.

Hernández-Romano, U., Aguilera-Franco, N., Buitrón, B.E., 1998, Late Cenomanian fossil association from Morelos, Mexico: stratigraphic implications: Revista Mexicana de Ciencias Geológicas, 15(1), 46-56.

Hurtado-Brito, J.C., Castillo-Delgado, I., 2009, Análisis sedimentológico de la Formación Mezcala en la parte norte-centro del estado de Guerrero, en los alrededores de Sabana Grande: Taxco el Viejo, Guerrero, Universidad Autónoma de Guerrero, tesis de licenciatura, 170 pp.

Hurtado-Brito, J.C., Ocampo-Díaz, Y.Z.E., Martínez-Paco, M., GuerreroSuategui, M., 2006, Sedimentación caracteristica de lóbulo-overbank y canales arenosos dentro de un sistema de abanicos medios en la región norte-centro del estado de Guerrero, en V Reunión Nacional de Ciencias de la Tierra: Puebla, Puebla, México, Sociedad Geológica Mexicana, 14.
Jordan, T., 1995, Retroarc foreland and related basins, en Busby. C.J., Ingersoll, R.V., (eds.), Tectonics of sedimentary basins: Cambridge, United States of America, Blackwell Science, 331-362.

Kneller, B., Edwards, D., McCaffrey, W., Moore, R., 1991, Oblique reflection of turbidity currents: Geology, 19(3), 250-252.

Lawton, F.T., Juárez-Arriaga, E., Ocampo-Díaz, Y.Z.E., Beltrán-Treviño, A., Martens, U., Stockli, D.F., 2016, Evolution of Late Cretaceous-Paleogene Foreland Sediment-Dispersal Systems of Northern and Central Mexico, en Lowery, C.M., Snedden, J.W., Rosen, N.C. (eds.), Mesozoic of the Gulf Rim and Beyond: New Progress in Science and Exploration of the Gulf of Mexico Basin: Houston, Texas, Gulf Coast Section Society of Economic Petrologists and Mineralogists, 283-308.

Leverenz, A., 2000, Trench-sedimentation versus accreted submarine fan - an approach to regional scale facies analysis in a mesozoic accretionary complex: Torlesse terrane, northeastern North Island, New Zealand: Sedimentary Geology, 132, 125-160.

Lomas, S.A., Joseph, P., 2004, Confined turbidite systems, en Lomas, S.A., Joseph, P., (eds.), Confined turbidite systems: London, Geological Society Special Publication 222, 1-7.

Martínez-Martinez, M., 1994, Estratigrafía, sedimentación y diagénesis de la secuencia cretácica en la región de Santa Teresa, Estado de Guerrero: Distrito Federal, México, Universidad Nacional Autónoma de México, tesis de licenciatura, $122 \mathrm{pp}$.

Martínez-Paco., M., 2009, Estudio litoestratigráfico de las secuencias cenozoicas, en el área de San Juan Tetelcingo, Guerrero: Taxco el Viejo, Guerrero, Universidad Autónoma de Guerrero, tesis de licenciatura, 78 pp.

Martini, M., Solari, L., López-Martínez, M., 2014, Correlating the Arperos basin from Guanajuato, central Mexico, to Santo Tomás, southern Mexico: Implications for the paleogeography and origin of the Guerrero terrane: Geosphere, 10(6), 1-17.

Mendoza, T.O., Suastegui, M.G., 2000, Geochemistry and isotopic composition of the Guerrero terrane (western Mexico): Implication for the tectonomagmatic evolution of southwestern north America during the Late Mesozoic: Journal of South American Earth Sciences, 13, 297-324.

Monod, O., Busnardo, R., Guerrero-Suastegui, M., 2000, Late Albian ammonites from the carbonate cover of the Teloloapan arc volcanic rocks (Guerrero State, Mexico): Journal of South American Earth Sciences, 13, 377-388.

Mulder, T., Razin, P., Faugeres, J.-C., 2009, Hummocky cross-stratificationlike structures in deep-sea turbidites: Upper Cretaceous Basque basins (Western Pyrenees, France): Sedimentology, 56(4), 997-1015.

Mutti, E., Normark, W., 1987, Comparig examples of modern and ancient turbidite system: Problems and concepts, en Leggett, K.J., Zuffa, G.G., (eds.), Marine clastic sedimentology: London, United Kingdom, Graham and Trotman, 1-38.

Mutti, E., Ricci-Lucchi, F., 1972, Le torbiditi dell' appennino settentrionale: Introduzione all'analisi di facies: Memorie della Societá Geologica Italiana, 11, 161-199.

Mutti, E., Tinterri, R., di Biase, D., Fava, L., Marvilla, N., Angella, S., Calabrese, L., 2000, Delta-front facies associations of ancient flood-dominated fluvio-deltaic systems: Revista de la Sociedad Geológica de España., 13(2), 165-190

Ocampo-Díaz, Y.Z.E., 2004, Análisis sedimentológico de la Formación Mezcala al norte del Estado de Guerrero: Taxco el Viejo, Guerrero, Universidad Autónoma de Guerrero, tesis de licenciatura, 167 pp.

Ocampo-Díaz, Y.Z.E., 2012, Historia deposicional de la Formación Mezcala en el sur de México: Sedimentología de los abanicos submarinos de la Formación Mezcala, norte del estado de Guerrero: Saarbrücken, Deutschland, Editorial Académica Española, 150 pp.

Ocampo-Díaz, Y.Z.E., Palacios-Castro, E., Rosendo-Brito, B., García-Ortiz, M., Buitrón, B.E., Guerrero-Suastegui, M., 2002, Tres nuevas localidades fosilíferas de la familia Inoceramidae dentro de la Formación Mezcala, al norte de Guerrero, en VII Congreso Nacional de Paleontología: Guadalajara, Jalisco, México, Sociedad Mexicana de Paleontología, 117.

Ocampo-Díaz, Y.Z.E., Pinzón-Sotelo, M.P., Chávez-Cabello, G., Ramírez-Díaz, A., Martínez-Paco, M., Velasco-Tapia, F., Guerrero-Suastegui, M., BarbozaGudiño, J.R., 2016, Propuesta nomenclatural y análisis de procedencia de la Formación Concepción del Oro (antes Formación Caracol): implicaciones sobre la evolución tectónica del sur de Norteamérica durante el Cretácico Tardío: Revista Mexicana de Ciencias Geológicas, 33(1), 3-33. 
Ontiveros-Tarango, G., 1973, Estudio estratigráfico de la porción noroccidental de la cuenca Morelos-Guerrero: Boletín del la Asociación Mexicana de Geólogos Petroleros, 25, 189-234.

Ortega-Gutíerrez, F., 1981, Metamorphic belts of southern Mexico and their tectonic significance: Geofísica Internacional, 20, 177-202.

Ortega-Gutiérrez, F., Elías-Herrera, M., Reyes-Salas, M., Macías-Romo, C. López, R., 1999, Late Ordovician-Early Silurian continental collisional orogeny in southern Mexico and its bearing on Gondwana-Laurentia connections: Geology, 27(8), 719-722.

Pickering, K.T., Hiscott, R.N., 1985, Contained (reflected) turbidity currents from the middle Ordovician Cloridorme Formation, Quebec, Canada: An alternative to the antidune hypothesis: Sedimentology, 32, 373-394.

Pickering, K.T., Hiscott, N.R., 2016, Deep marine systems: Processes, deposits, environments, tectonics and sedimentation: London, United Kingdom, Wiley, 657 pp.

Pickering, K.T., Bassett, M.G., Siveter, D.J., 1988, Late Ordovician-early Silurian destruction of the Iapetus Ocean: Newfoundland, British Isles and Scandinavia- a discussion: Transactions of the Royal Society of Edinburgh, Earth Sciences, 79, 361-382.

Ramírez-Espinosa, J., 2001, Tectono-magmatic evolution of the Paleozoic Acatlán complex in southern Mexico, and its correlation with the Appalachian System: Tucson, Arizona, University of Arizona, tesis doctoral, $171 \mathrm{pp}$.

Ramírez-Espinosa., J., Campa-Uuranga, M.F., Talavera-Mendoza, O., GuerreroSuastegui, M., 1991, Caracterización de los arcos insulares de la Sierra Madre del Sur y sus implicaciones tectónicas; en Convención sobre la evolución Geológica de México: Pachuca, Hidalgo, Sociedad Mexicana de Mineralogía e Instituto de Geología, Universidad Nacional Autónoma de México, 163.

Reading, H.G., Richards, M.T., 1994, The classification of deep-water siliciclastic depositional systems by grain size and feeder system: American Association of Petroleum Geologists Bulletin, 78, 792-822.

Ricci-Lucchi, F., 1986, The Oligocene to recent foreland basins of the northern Apennines, en Allen, P. A., Homewood, P., (eds.), Foreland basins: London, Blackwell Publishing Ltd., 103-139.

Rosendo-Brito, B., Ocampo-Díaz, Y.Z.E., Buitrón, B.E., Garibay-Romero, L.M., 2002, Crinoides planctónicos (crinodea, roveacrinidae) del Cretácico Superior de Cerro Gordo, municipio de Taxco de Alarcón, Guerrero, en VIII Congreso Nacional de Paleontología: Guadalajara, Jalisco, México, Sociedad Mexicana de Paleotología, 79.

Sierra-Rojas, M.I., Molina-Garza, R., Lawton, T.F., 2016, The Lower Cretaceous Atzompa Formation in south-central Mexico: Record of evolution from extensional back-arc basin margin to carbonate platform: Journal of Sedimentary Research, 86, 712-733.
Talavera-Mendoza, O., 1993, Les formations orogeniques mesozoiques du Guerrero (Mexique meridional). Contribution à la connaisance de l'évolution géodynamique des cordillères mexicaines: Paris, France, Université Joseph Fourier, tesis doctoral, 462 pp.

Talavera-Mendoza, O., 2000, Mélanges in southern Mexico: Geochemistry and metamomorphism of Las Ollas complex (Guerrero terrane): Canadian Journal of Earth Sciences, 37, 1309-1320.

Talavera-Mendoza, O., Ramírez-Espinosa, J., Guerrero-Suastegui, M., 1995, Petrology and geochemistry of the Teloloapan subterrane, a Lower Cretaceous evolved intra-oceanic island-arc: Geofísica Internacional, 34, 3-22.

Talavera-Mendoza, O., Ruiz, J., Gehrels, G.E., Valencia, V.A., Centeno-García, E., 2007, Detrital zircon U/Pb geochronology of southern Guerrero and western Mixteca arc successions (southern Mexico): New insights for the tectonic evolution of southwestern North America during the Late Mesozoic: Geological Society of America Bulletin, 119(9-10), 1052-1065.

Tardy, M., Lapierre, H., Freydier, C., Coulon, C., Gill, J.B., Mercier de Lepinay, B., Beck, C., Martínez, R.J., Talavera, M.O., Ortiz, H.E., Bourdier, J.L., Yta, M., 1994, The Guerrero suspect terrane (western Mexico) and coeval arc terranes (the Greater Antilles and the western Cordillera of Colombia): A Late Mesozoic intra-oceanic arc accreted to cratonal America during the Cretaceous: Tectonophysics, 230, 49-73.

Underwood, M.B., 1984, A sedimentologic perspective on stratal distruption within sandstone-rich melange terranes: Journal of Geology, 92, 369-385.

Wynn, R.B., Kenyon, N.H., Masson, D.G., Stow, D.A.V., Weaver, P.P.E., 2002a, Characterization and recognition of deep-water channel-lobe transition zones: American Association of Petroleum Geologists Bulletin, 86(8), 1441-1462.

Wynn, R.B., Piper, D.J.W., Gee, M.J.R., 2002b, Generation and migration of coarse-grained sediment waves in turbidity current channels and channellobe transition zones: Marine Geology, 192, 59-78.

Manuscrito recibido: marzo 10, 2017

Manuscrito corregido recibido: enero 28, 2018

Manuscrito aceptado: febrero 12, 2018 